University of Nebraska - Lincoln

DigitalCommons@University of Nebraska - Lincoln

USDA Forest Service / UNL Faculty Publications U.S. Department of Agriculture: Forest Service -National Agroforestry Center

2003

\title{
Remote Sensing Estimates of Boreal and Temperate Forest Woody Biomass: Carbon Pools, Sources, and Sinks
}

\author{
Jiarui Dong \\ Boston University, 675 Commonwealth Avenue, Boston, MA \\ Robert Kaufmann \\ Boston University, 675 Commonwealth Avenue, Boston, MA \\ Ranga Myneni \\ Boston University, 675 Commonwealth Avenue, Boston, MA \\ Compton Tucker \\ NASA Goddard Space Flight Center, compton.j.tucker@nasa.gov \\ Pekka Kauppi \\ Department of Limnology and Environmental Protection, University of Helsinki, P.O. Box 27, FIN-00014 \\ Helsinki, Finland \\ See next page for additional authors \\ Follow this and additional works at: https://digitalcommons.unl.edu/usdafsfacpub \\ Part of the Forest Sciences Commons
}

Dong, Jiarui; Kaufmann, Robert; Myneni, Ranga; Tucker, Compton; Kauppi, Pekka; Liski, Jari; Buermann, Wolfgang; Alexeyev, V.; and Hughs, Malcolm, "Remote Sensing Estimates of Boreal and Temperate Forest Woody Biomass: Carbon Pools, Sources, and Sinks" (2003). USDA Forest Service / UNL Faculty Publications. 43.

https://digitalcommons.unl.edu/usdafsfacpub/43

This Article is brought to you for free and open access by the U.S. Department of Agriculture: Forest Service -National Agroforestry Center at DigitalCommons@University of Nebraska - Lincoln. It has been accepted for inclusion in USDA Forest Service / UNL Faculty Publications by an authorized administrator of DigitalCommons@University of Nebraska - Lincoln. 


\section{Authors}

Jiarui Dong, Robert Kaufmann, Ranga Myneni, Compton Tucker, Pekka Kauppi, Jari Liski, Wolfgang

Buermann, V. Alexeyev, and Malcolm Hughs 


\title{
Remote sensing estimates of boreal and temperate forest woody biomass: carbon pools, sources, and sinks
}

\author{
Jiarui Dong ${ }^{a, *}$, Robert K. K aufmann ${ }^{a}$, Ranga B. M yneni ${ }^{a}$, Compton J. Tucker ${ }^{b}$, \\ Pekka E. Kauppi ${ }^{c}$, Jari Liski ${ }^{d, e}$, Wolfgang Buermann ${ }^{a}$, V. A lexeyev ${ }^{f}$, M alcolm K. Hughes ${ }^{g}$ \\ ${ }^{a}$ Department of Geography, Boston University, 675 Commonwealth Avenue, Boston, MA 02215-1401, USA \\ ${ }^{\text {b} N A S A ~ G o d d a r d ~ S p a c e ~ F ~ l i g h t ~ C e n t e r, ~ C o d e ~ 923, ~ G ~ r e e n b e l t, ~ M D ~ 20771, ~ U S A ~}$ \\ ${ }^{c}$ D epartment of Limnology and Environmental Protection, U niversity of Helsinki, P.O. Box 27, FIN-00014 Helsinki, Finland \\ ${ }^{\mathrm{d}}$ European Forest Institute, Torikatu 34, FIN-80100 J oensuu, Finland \\ ${ }^{\text {e}}$ Department of F orest Ecology, U niversity of Helsinki, P.O. Box 27, FIN-00014 Helsinki, Finland \\ ${ }^{f}$ The Saint-Petersburg F orest Ecological Center, 21 Instituskii Av. St. Petersburg, 194021, Russia \\ ${ }^{9}$ Laboratory of Tree-Ring Research, U niversity of Arizona, Tucson, AZ 85721, USA
}

Received 28 A ugust 2001; received in revised form 4 February 2002; accepted 26 A ugust 2002

\begin{abstract}
The relation between satellite measurements of the normalized difference vegetation index (NDVI), cumulated over the growing season, and inventory estimates of forest woody biomass carbon is estimated statistically with data from 167 provinces and states in six countries (Canada, Finland, Norway, Russia and the USA for a single time period and Sweden for two periods). Statistical tests indicate that the regression model can be used to represent the relation between forest biomass and NDVI across spatial, temporal and ecological scales for relatively long time scales. For the 1.42 billion ha of boreal and temperate forests in the $\mathrm{N}$ orthern Hemisphere, the woody biomass carbon pools and sinks are estimated at a rel atively high spatial resolution $(8 \times 8 \mathrm{~km})$. We estimate the carbon pool to be $61 \pm 20$ gigatons ( $\left.10^{9}\right)$ carbon $(\mathrm{Gt} \mathrm{C})$ during the late 1990s and the biomass sink to be $0.68 \pm 0.34 \mathrm{Gt} \mathrm{C/year} \mathrm{between} \mathrm{the} 1982$ and 1999. The geographic detail of carbon sinks provided here can contribute to a potential monitoring program for greenhouse gas emission reduction commitments under the $\mathrm{K}$ yoto Protocol. (C) 2002 Elsevier Science Inc. All rights reserved.
\end{abstract}

Keywords: Forest biomass pools; Sources and sinks; Kyoto Protocol; Remote sensing; NDVI; Forest inventory

\section{Introduction}

The terrestrial carbon cycle is a highly dynamic system that includes several storage pools, such as vegetation, soil, detritus, black carbon residue from fires, harvested products, etc, which can be characterized by their turnover time (Schulze, Wirth, \& Heimann, 2000). Carbohydrate pools turn over on a daily basis, leaves can store carbon for several seasons and carbon in living wood and soil pools may remain there for millennia. Fire may return carbon to the atmosphere instantaneously and can produce long-lived black carbon. $M$ any studies, including B ousquet et al. (2000), suggest that about 1-2 Gt carbon are sequestered annually in pools on

\footnotetext{
* Corresponding author. Present address: Hydrological Science B ranch, NASA Goddard Space Flight Center Greenbelt, M D 20771, USA.

E-mail address: jiarui@ hsb.gsfc.nasa.gov (J. Dong).
}

land in temperate and boreal regions. Such sinks represent $15-30 \%$ of annual anthropogenic carbon emissions. The use of carbon sinks in policies to reduce greenhouse gas emissions presently is being debated (IPCC, 2000). Thus, characterizing the location and mechanism of carbon sinks is of scientific and political importance.

Forests play a major role in the global carbon budget because they dominate the dynamics of the terrestrial carbon cycle. Studies are currently afoot for assessing the use of forest biomass sinks to sequester carbon as part of a global mitigation effort (Sedjo \& Toman, 2001). These studies emphasize the importance of forests in the carbon cycle and the need to quantify, measure, monitor and manage carbon pools in forests. Forests contain about $60 \%$ of the carbon stored in vegetation and about $50 \%$ of the carbon stored in soil (TBFRA -2000, 2000). Of these totals, a large percentage of the vegetation (41\%) and soil (72\%) pools are located between $25^{\circ} \mathrm{N}$ and $75^{\circ} \mathrm{N}$ (Dixon, Houghton, Solomon, Trexler, 
\& Wisniewski, 1994). Consistent with these fractions, this study analyzes the carbon stored in the woody biomass of temperate and boreal forests, which cover an area of about 1.4-1.5 billion ha (Liski \& Kauppi, 2000). Due to limits associated with remotely sensed data, we focus on live forest biomass, rather than dead biomass and soil carbon. Consistent with previous uses of remotely sensed data, we define forests to include the following remote sensing land covers (H ansen, D eF ries, Townshend, \& Sohlberg, 2000): broad leaf forests, needle leaf forests, mixed forests and woody savannas. These land covers are broadly consistent with land use definitions of a forest, but not forest and other wooded land (Liski \& Kauppi, 2000). Woody biomass includes wood, bark, branches, twigs, stumps and roots of trees, shrubs and bushes. This pool gains carbon from productivity investment in these components and loses carbon due to harvest, fire, disease, insect attacks, windthrow, etc.

National Forest Resource Inventories for most countries have detailed and reliable information on forest distribution and changes over 5-year periods (e.g., Birdsey \& Heath, 1995; Fang, Chen, Peng, Zhao, \& Ci, 2001; Liski \& K auppi, 2000; L owe, Power, \& Gray, 1996; Turner, K oerper, Harmon, \& Lee, 1995). However, inventory data are available for certain countries and regions only, and the quality of these data varies substantially among inventories. For example, no data are available for remote regions in Canada, R ussia and elsewhere. Satellite observations of vegetation provide global coverage with relatively high spatial resolution over the last two decades. Biomass cannot be directly measured from space, but, as we demonstrate below, remotely sensed greenness can be used to estimate biomass on decadal and longer time scales. Year-to-year changes in biomass are quite small, about two orders of magnitude smaller than the biomass pool, unlike year-to-year changes in greenness, which can vary 5 $10 \%$ relative to the seasonal average due to climate variability (M yneni, Tucker, A srar, \& K eeling, 1998). At decadal and longer time scales, biomass can change considerably due to cumulative differences between annual gains and losses. These can be observed as low-frequency variations in climatological greenness, in much the same way that changes in greenness at century and longer time scales suggest successional changes.

In this paper, we investigate the relation between satellite-derived greenness and inventory estimates of forest woody biomass carbon content (Section 2) and evaluate the ability of regression models to represent the relation
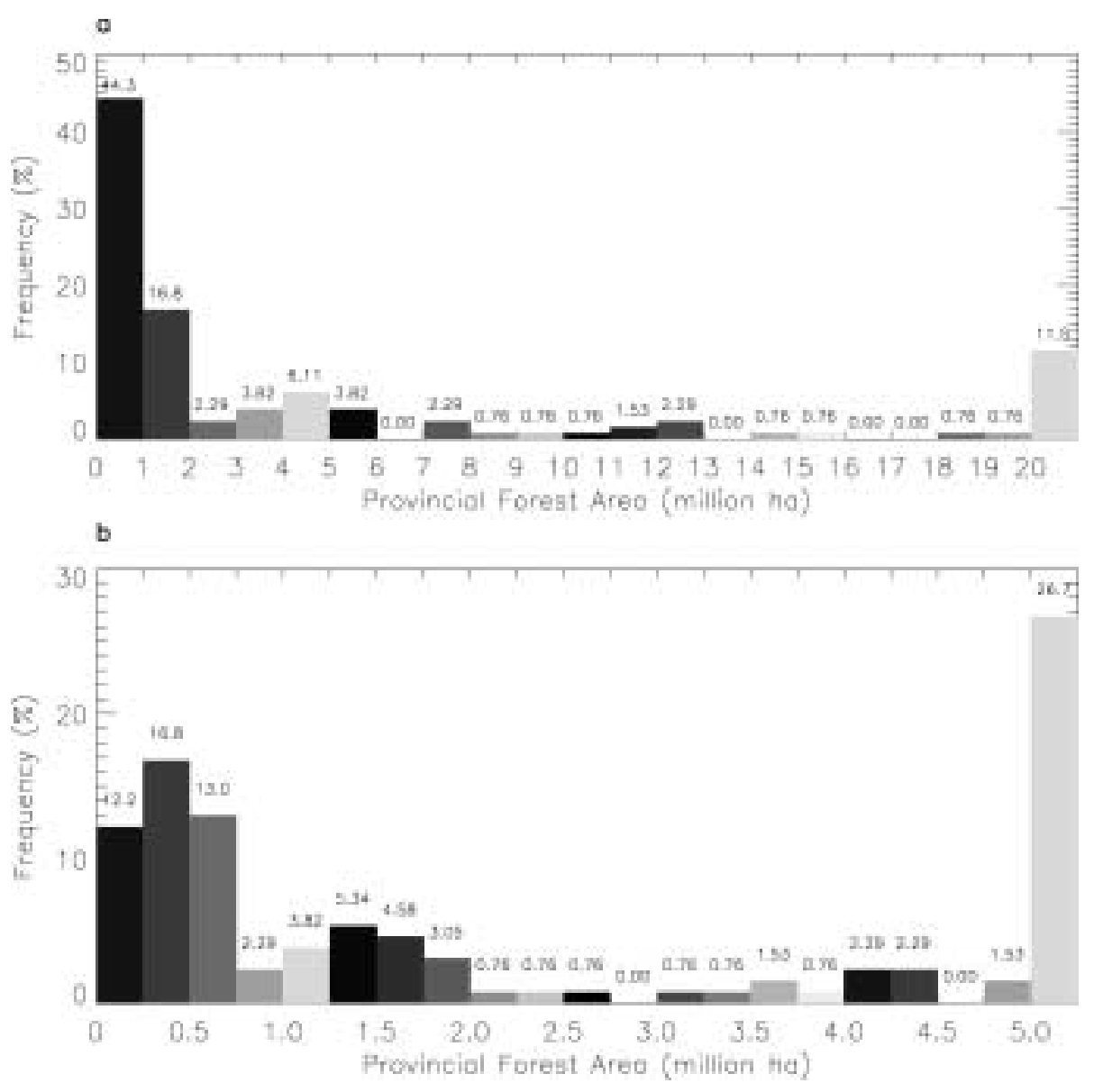

Fig. 1. Distribution of provincial and state forest areas in Canada, Finland, N orway, Russia and the USA (single time period) and Sweden (two time periods) at 1 million- (a) and 0.25 million-ha (b) intervals. 
between biomass and NDVI across spatial, temporal and ecological scales (Section 3). Remote sensing estimates of forest woody biomass carbon pools and changes are described in Section 4, where we also provide uncertainty analysis in remote sensing estimates relative to inventory data with special emphasis on Canada, China, Russia and the USA.
2. Satellite NDVI and forest inventory data

\subsection{GIMMS NDVI data}

A global NDVI data set at $8 \times 8-\mathrm{km}$ resolution for the period July 1981 to December 1999 was developed from about 40,000 orbits of daily data from the A dvanced Very
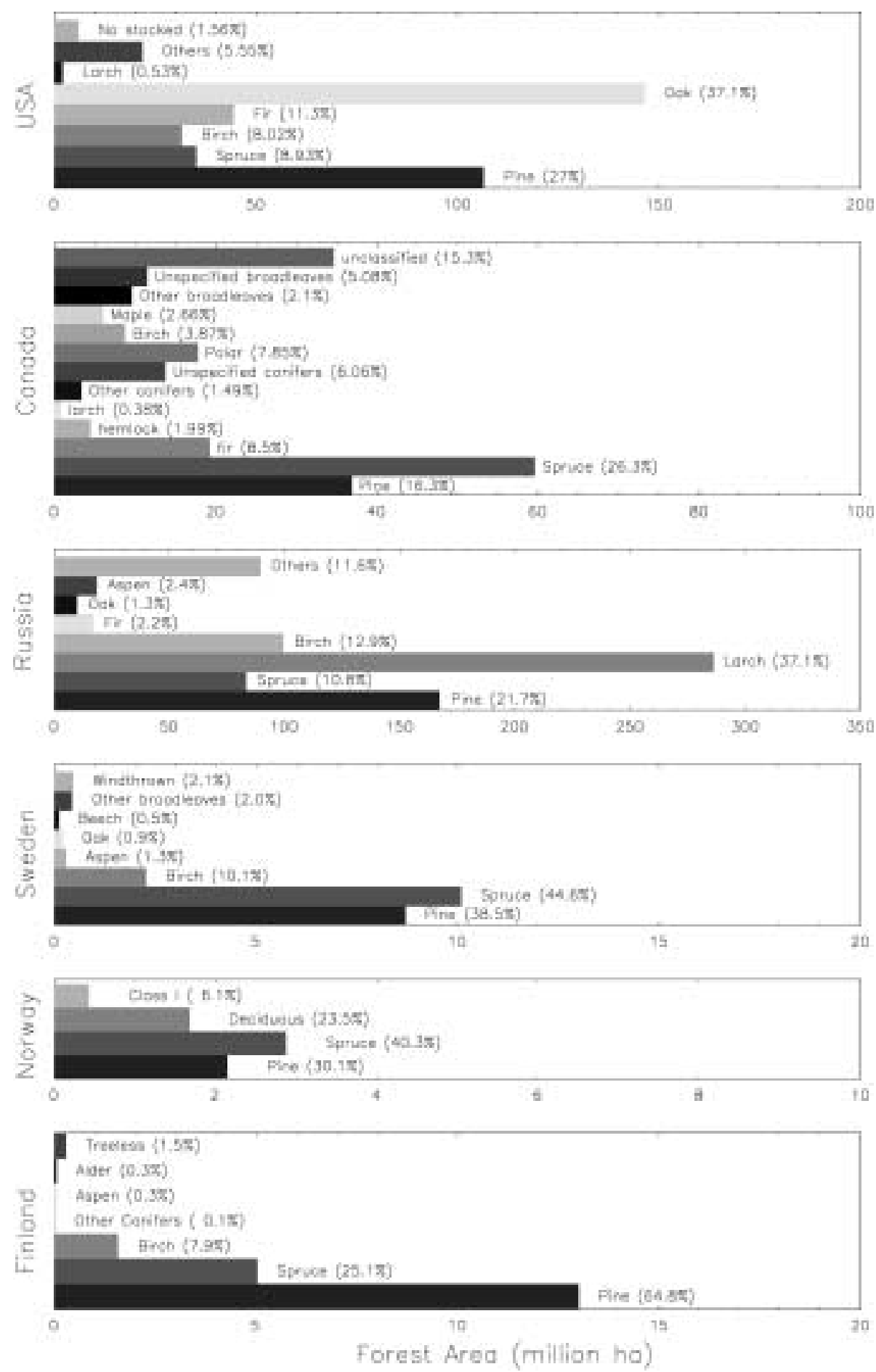

Fig. 2. Distribution of forests area by genus in the six sample countries (The USA, Canada, Russia, Sweden, Norway, and Finland). 
High Resolution Radiometers (AVHRR) on board the NOAA -7, $-9,-11$ and -14 satellites by the Global Inventory Monitoring and Modeling System (GIMMS) group. The normalized difference vegetation index (NDVI) measures the contrast between red and near-infrared reflection of solar radiation and can be used to proxy green leaf area (M yneni et al., 1998). NDVI varies between -1 and +1 , and increases from about 0.1 to 0.75 for increasing amounts of vegetation but saturates in the case of dense leaf canopies, for example, humid tropical forests and old growth forests. Growing season NDVI is determined by two dimensions: the length of the growing season and the magnitude of observations. As such, growing season NDVI is an ideal measure of seasonal greenness.

The processing of satellite data involved cloud screening and calibration for sensor degradation and inter-sensor variations (L 0S, 1998; LoS, Justice, \& Tucker, 1994; Rosborough, B aldwin, \& Emery, 1994; Vermote \& K aufman, 1995). Residual atmospheric effects were minimized by analyzing only the maximum NDVI value within each 15-day interval. These data generally correspond to observations from near- nadir viewing directions (Los et al., 1994) and clear atmospheric conditions (Holben, 1986). The data from A pril 1982 to December 1984 and from J une 1991 to December 1993 were corrected to remove the effects of stratospheric aerosol loadings from EI Chicon and Mount Pinatubo eruptions in mid- and high latitudes of the N orthern Hemisphere, respectively (Vermote $\&$ EI Saleous, 1994). Further details on the quality of the GIMMS NDVI data set can be found in K aufmann et al. (2000) and Zhou et al. (2001).

\subsection{Forest inventory data}

Inventory data for stem wood volume from 171 provinces in six countries (Canada, Finland, Norway, Russia, Sweden and USA) that cover over 1 billion ha of forest area are analyzed to estimate above-stump and total biomass. The total number of provinces and states in the six countries is 182. Of these, data from 171 provinces where forest area covers more than $15 \%$ of the land area (10\% in Russia) are used in the following analysis. A bout $44 \%$ of the provinces have forested area less than 1.0 million ha (29\% less than
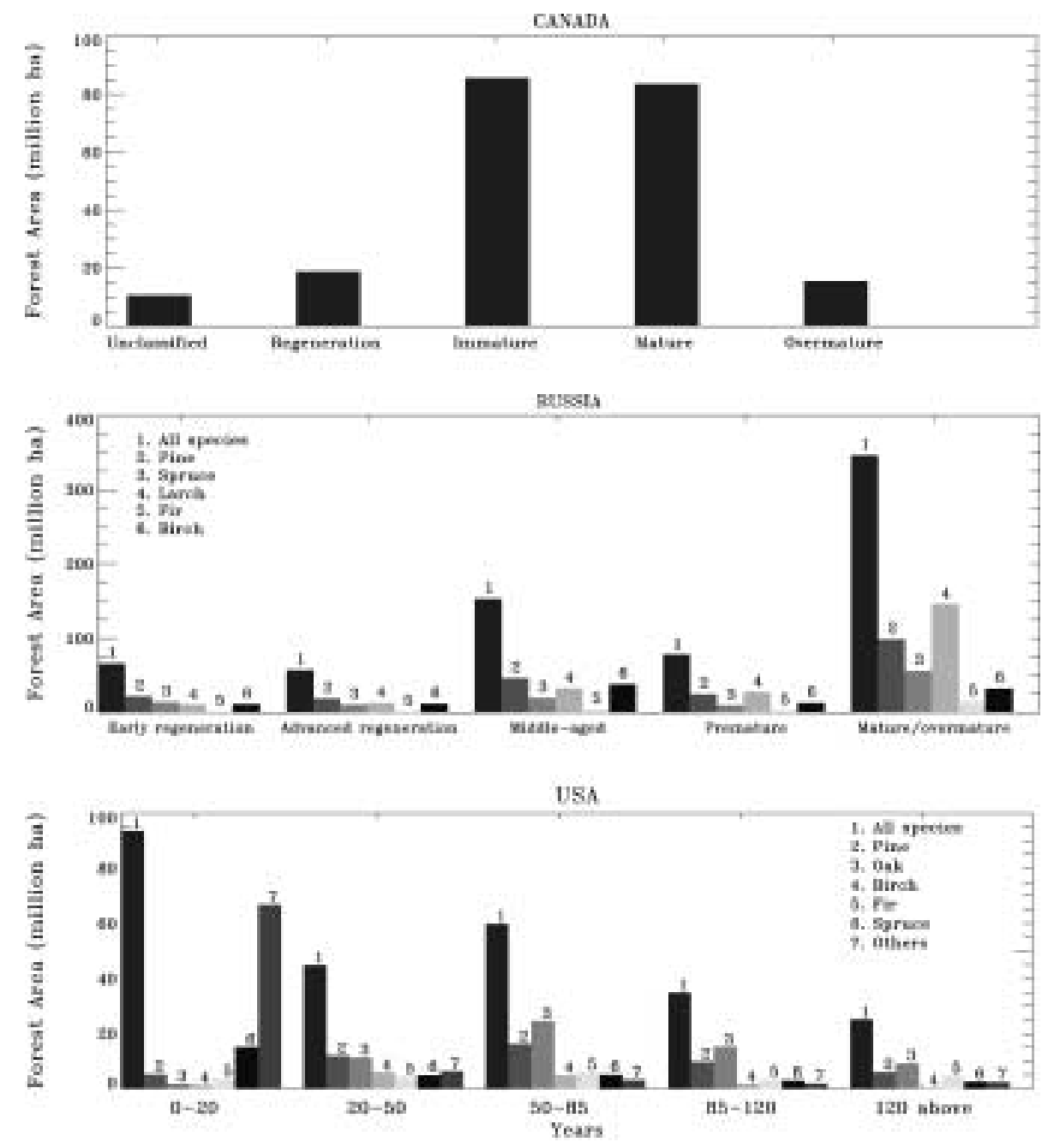

Fig. 3. A ge structure of forest in Canada, Russia and the USA. 
0.5 million ha), and about $27 \%$ have areas greater than 5 million ha (11.5\% greater than 20 million ha) (Fig. 1). The dominant forest type is needle leaf (spruce, pine, fir and other conifers in Canada, greater than $60 \%$; larch, pine and spruce in Russia, greater than $70 \%$; spruce and pine in Finland, Norway and Sweden, about 70-90\%). The area under broad leaf forest (mostly oak) in the USA is comparable to that of needle leaves (pine, fir and spruce), about $40 \%$ (Fig. 2). A bout $40 \%$ of the forest area in Canada and $55 \%$ in Russia is mature or overmature forests. The area under immature forests in Canada is about 30\% (23\% middle-aged forests in Russia). The area under regeneration is less than $10 \%$ in Canada (20\% in Russia) (Fig. 3). Thus, in a broad sense, the Canadian and Russian forest age structures are comparable. In the USA, fully three-fourths of the forest area includes forests younger than 85 years, but these data probably are $10-20$ years old. These three large countries account for $77 \%$ of the forest area north of $30^{\circ} \mathrm{N}$.

The inventory data have information on wood volume. A bove-stump biomass, the oven-dry weight in tons/ha of various biological components, is estimated from inventoried wood volume for needle leaf and broadleaf forests using Eq. (1)

$A B(P)=\frac{N_{c f}(C) W V_{N}(P)+B_{c f}(C) W V_{B}(P)}{F A(P)}$,

where $A B$ is above-stump biomass (tons/ha), $N_{c f}$ is the conversion factor for conifers (tons biomass $/ \mathrm{m}^{3}$ stem wood), $\mathrm{B}_{\mathrm{cf}}$ is the conversion factor for broad leaves (tons biomass/ a

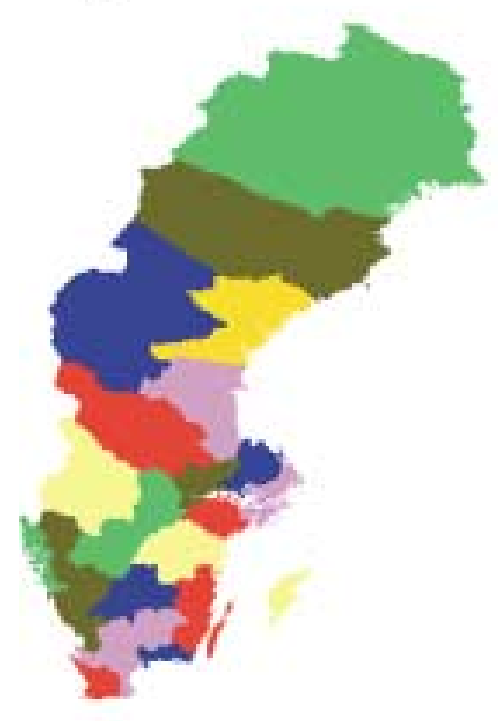

b

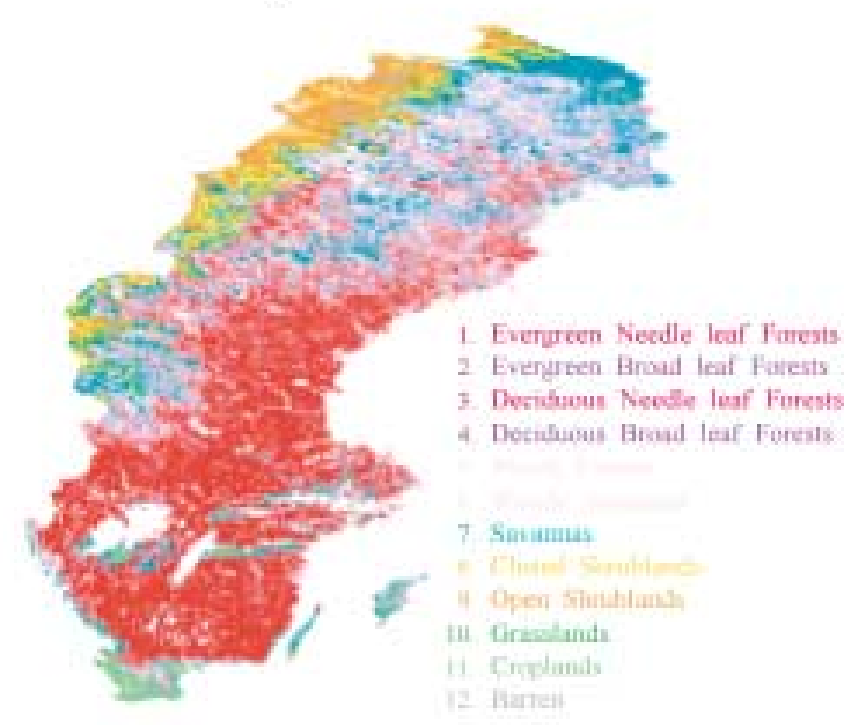

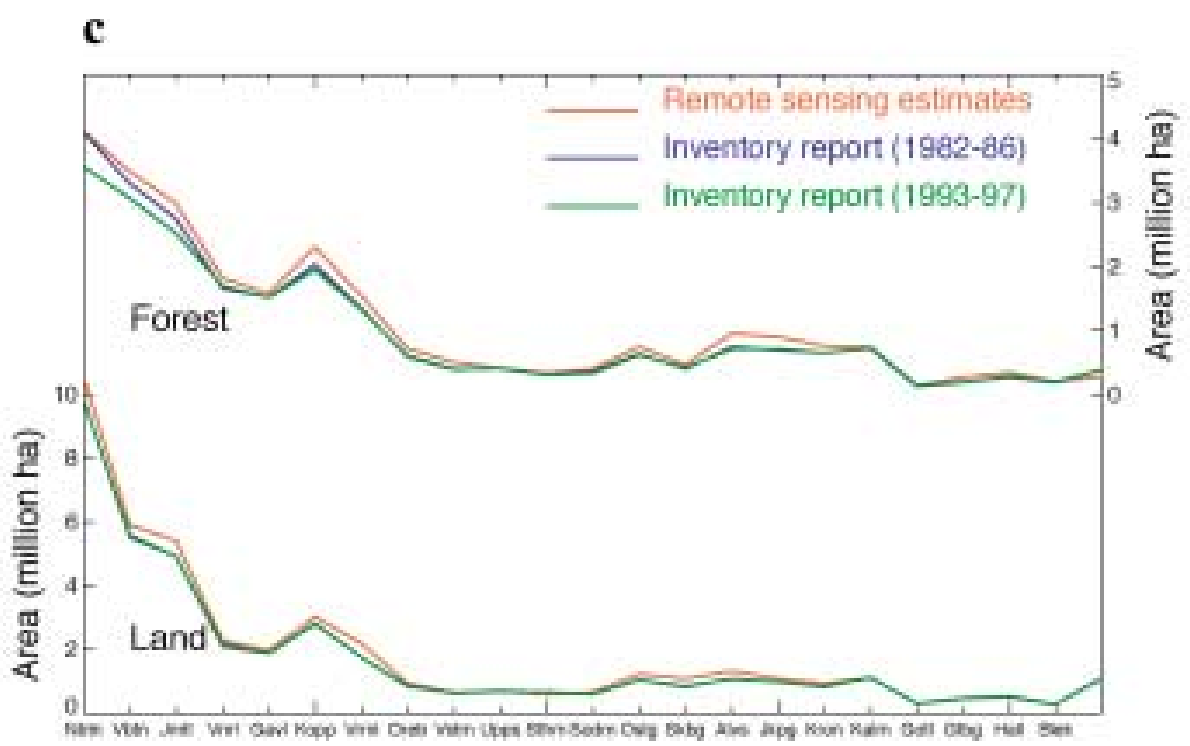

Fig. 4. A n example to match inventory data and satellite NDVI. (a) A dministrative map of Sweden with 24 provinces for which the inventory data are available; (b) land cover map at a spatial resolution of $1 \times 1 \mathrm{~km}$; (c) forest and land area from remote sensing estimates and inventory reports. 
$\mathrm{m}^{3}$ stem wood), $W V_{N}$ is wood volume of needle leaf forest $\left(m^{3}\right), W V_{B}$ is wood volume of broad leaf forest $\left(m^{3}\right)$ and $F A$ is forest area (ha). The values for $A B, W V_{N}$ and $W V_{B}$ are derived for inventory data for individual provinces, and the values for $\mathrm{N}_{\mathrm{cf}}$ and $\mathrm{B}_{\mathrm{cf}}$ are assigned for individual countries. Total biomass is estimated by adding the root biomass,

$\mathrm{TB}(\mathrm{P})=\mathrm{AB}(\mathrm{P})\left[1+\left(\frac{\mathrm{FF}(\mathrm{P})}{\mathrm{N}_{\mathrm{cf}}(\mathrm{C})}+\frac{\mathrm{FF} \mathrm{F}_{\mathrm{B}}(\mathrm{P})}{\mathrm{B}_{\mathrm{Cf}}(\mathrm{C})}\right) \mathrm{R}_{\mathrm{Cf}}(\mathrm{C})\right]$

where $T B$ represents the total biomass (tons/ha), $F F_{N}$ is forest fraction of conifers (\% of pixel area), $\mathrm{FF}_{\mathrm{B}}$ is forest fraction of broad leaves (\% of pixel area) and $R_{c f}$ is conversion factors for roots (tons biomass $/ \mathrm{m}^{3}$ stem wood).
The conversion factors are country specific and are obtained from the Temperate and Boreal Forest Resources A ssessment (TBFRA-2000, 2000).

\subsection{Matching inventory and remote sensing data}

The relation between biomass and cumulative growing season N DV I data requires matching inventory data to remote sensing data, such that the growing season NDVI totals are calculated using pixels for forest land covers only. The methodology used to match inventory and remotely sensed data are described below using Sweden as an example.

Sweden spans a latitude range of about $55^{\circ} \mathrm{N}$ to $70^{\circ} \mathrm{N}$, and includes 23 provinces for which inventory data are
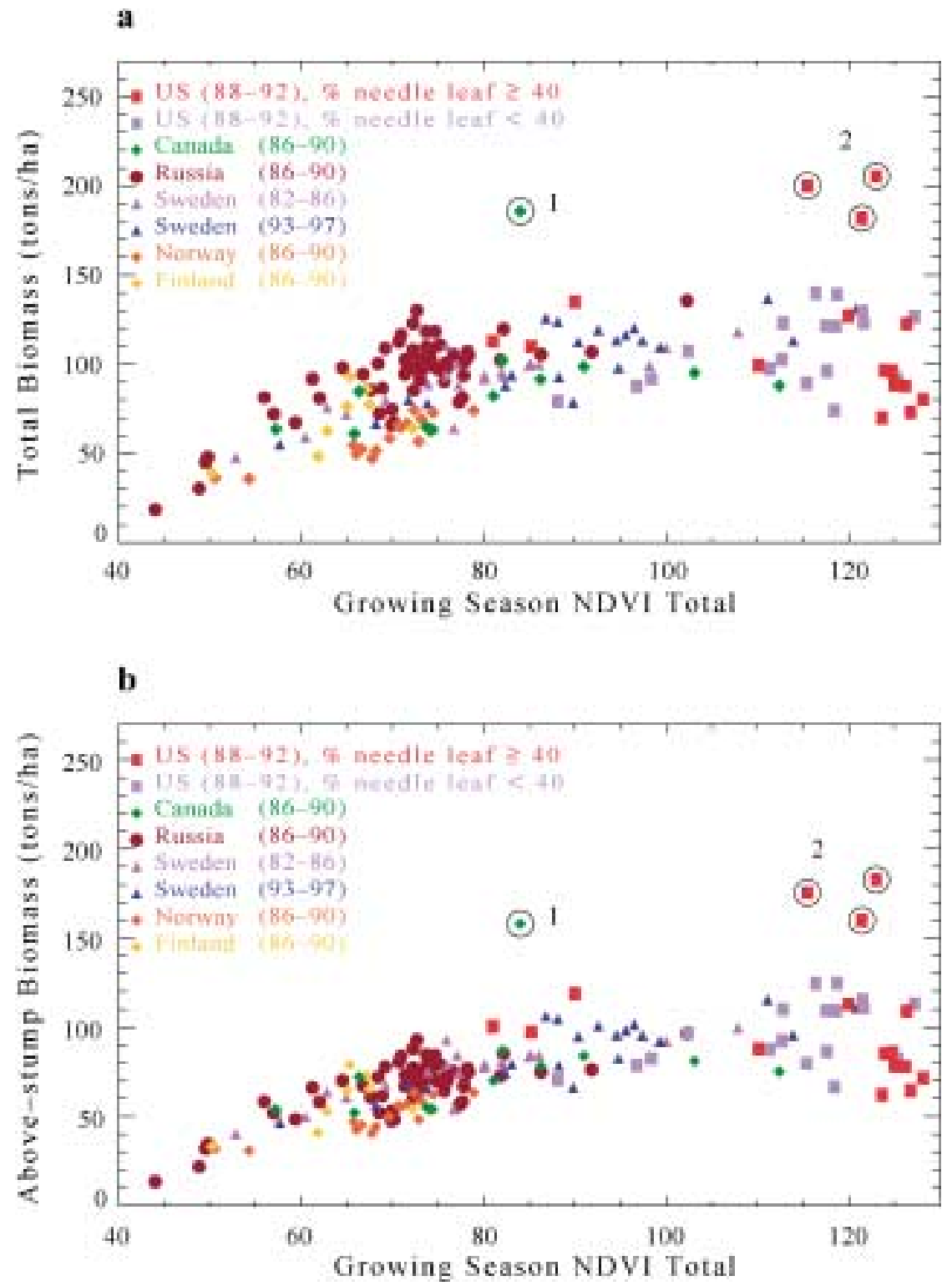

Fig. 5. Plot of total (a) and above-stump (b) woody biomass versus cumulative growing season NDVI. The NDVI data are 5-year averages prior to the date of inventories. Outlier 1 is B ritish Columbia (Canada) and outliers 2 are data from Washington, Oregon and (northern) California (USA). These represent $16 \%$ of North A merican forest area. 
available (Fig. 4a). These data include stem wood volume in million cubic meters and forest area in thousand hectares for various tree types and trunk size classes. Data are published in a series of statistical handbooks. We use data from two periods (1982- 1986 and 1993-1997).

To match these provincial inventory estimates to the $8 \times 8-\mathrm{km}$ pixel data for NDVI, we map the distribution of forest area in each of the provinces, not just the total forest area. To do so, we use a remote sensing land cover map (Fig. 4b). This map has a spatial resolution of $1 \times 1 \mathrm{~km}$ (Hansen et al., 2000). Using this map to define data layers in a Geographical Information System, we calculate the cumulative growing season greenness for all forest pixels. Forests include the following remote sensing land covers: broad leaf forests, needle leaf forests, mixed forests and woody savannas. This ensures that the resulting provincial cumulative growing season greenness data are assembled from the NDVI for forested regions only. A Iso, comparing estimates for total forest area generated from inventory and remote sensing data allow us to validate the methodology. This comparison is shown in Fig. 4c. The inventory stem wood volume data are converted to total and above-stump biomass, as described above, and plot against the provincial growing season cumulation NDVI (see triangles in Fig. 5).

\section{R egression analysis of biomass and satellite greenness} data

\subsection{The biomass-NDVI equation}

The relation between NDVI and inventory estimates for above-stump biomass and total biomass are shown in Fig. 5 for all seven samples. The three outliers that are associated with growing season NDVI values beyond 110 are observations from the US temperate forests, where biomass is either uncharacteristically low (southeastern states) or high (pacific northwestern states). The relationship between biomass and NDVI is estimated from the sample data (without outliers) using the following equation:

$$
1 / \text { Biomass }=\alpha+\beta\left[(1 / \text { NDVI }) / \text { Latitude }^{2}\right]+\gamma \text { L atitude },
$$

in which Biomass is a measure of total or above-stump biomass obtained from inventory, NDVI is the cumulative growing season NDVI averaged over a 5-year period prior to inventory date, Latitude is the centroid of the area sampled by forest inventory in a province, and $\alpha, \beta$ and $\gamma$ are regression coefficients. The value of these coefficients is estimated using ordinary least squares. For total biomass, they are $\alpha=-0.0377( \pm 0.00977), \beta=3809.65( \pm 902.51)$ and $\gamma=0.0006( \pm 0.00011)$ adjusted $R^{2}=0.43$. For abovestump biomass they are, $\alpha=-0.0557( \pm 0.0136), \beta=$ $5548.05( \pm 1274.17)$ and $\gamma=0.000854( \pm 0.000153)$ adjusted $R^{2}=0.49$. Values in parentheses are standard errors.
Eq. (3) specifies the relation between NDVI and biomass $\left[(1 / N D V I) /\right.$ atitude $\left.^{2}\right]$, such that this relation can vary across space. Over large spatial scales, biomes vary by latitude, with low biomass boreal forests at high latitudes and high biomass hardwood forests at mid-latitudes. This latitudinal variation probably is not linear. Biomass increases with latitude north of $25-30^{\circ} \mathrm{N}$, where most of the world's deserts are located. To capture this nonlinear variation, we divide NDVI by the square of latitude. This specification implies that the amount of biomass that is associated with a given level of NDVI varies with latitude with the largest values in temperate latitudes (Fig. 6a). Similarly, the relation between biomass and NDVI varies with latitude (Fig. $6 b)$.

\subsection{Evaluation of the biomass - NDVI equation}

Estimating the biomass- NDV I equation from pooled data implies that the relation between biomass and NDV I does not vary among the seven samples. A s noted above, the data used to estimate the biomass-NDVI equation represent a wide variety of inventory practices, provincial forest acreage, ecosystem types, age structures, management practices, fire and insect dynamics and time periods. These differences could cause the biomass-NDVI equation to indicate a relation between biomass and NDVI when in fact no relation exists and/or could bias the statistical estimates for the regression coefficients (Hsiao, 1986). Such problems would affect the reliability of our estimate for biomass and ultimately, the carbon sink. B ecause of these potential problems, using the seven samples to estimate the relation between biomass and NDVI for all of N orth A merica and Eurasia begs two related questions: (1) does the relation between biomass and NDVI vary across spatial, temporal and ecological scales; (2) if the relation does vary, can Eq. (3) be used to generate accurate estimates for biomass (and changes in biomass) in countries where there are no forest inventory data to generate country-specific relations?

One way to evaluate the ability of the biomass-NDVI equation to represent the relation between biomass and NDVI across spatial, temporal and ecological scales is to test the null hypothesis that the regression coefficients do not vary across the seven samples used to estimate the equation. This null hypothesis is tested by comparing a restricted model, in which the value of the regression coefficients do not vary among samples, against an unrestricted model, in which the values of the regression coefficients are allowed to vary. From this perspective, Eq. (3) can be considered to be a restricted version of the following unrestricted model in which the intercepts are allowed to vary across the seven samples as

$1 /$ Biomass $=\sum_{i=1}^{7} \alpha_{i}+\beta\left[(1 /\right.$ NDVI $) /$ Latitude $\left.^{2}\right]+\gamma$ Latitude, 

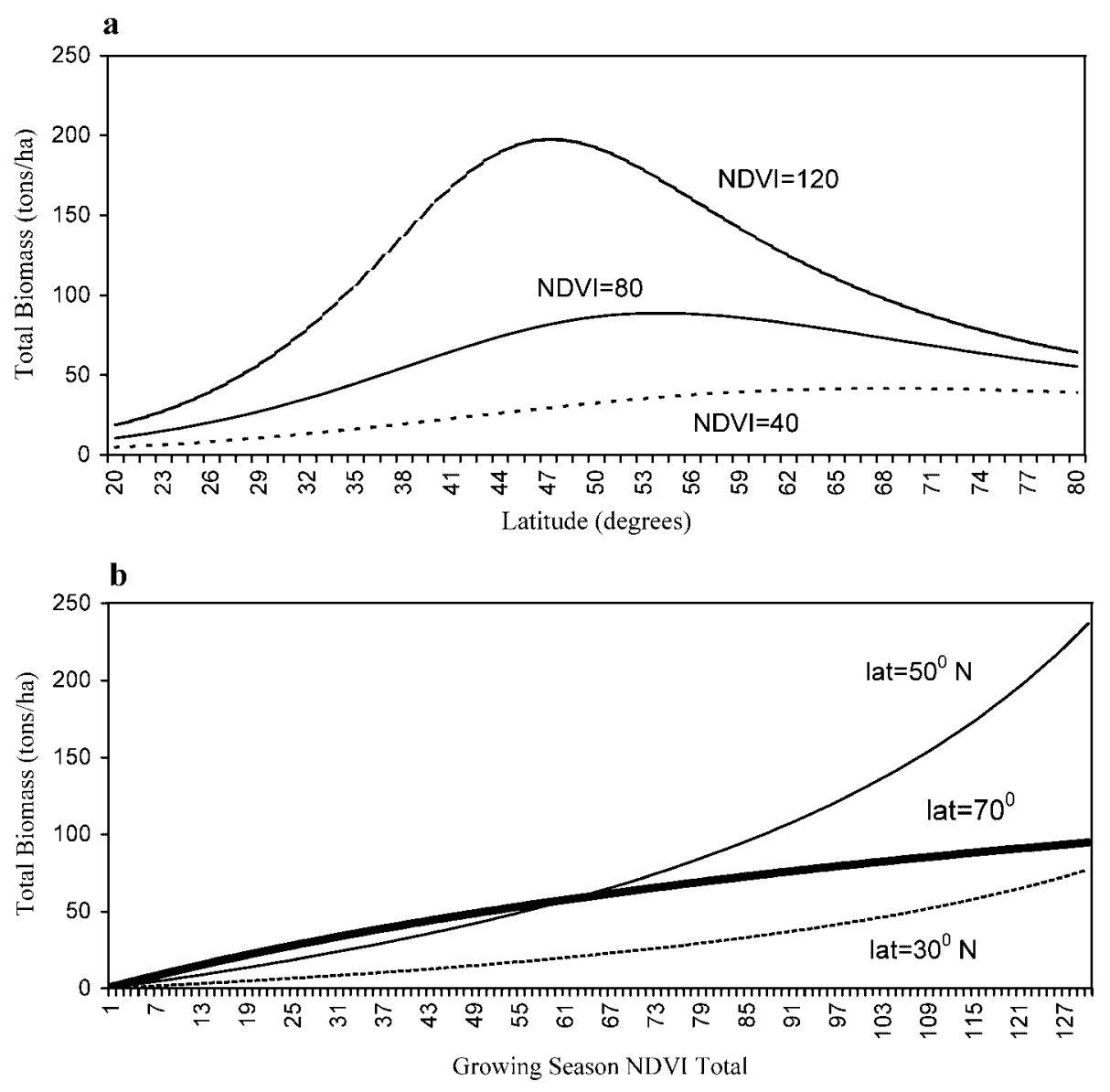

Fig. 6. The relations (a) between total biomass and latitude at three levels of total growing season N DVI and (b) between total biomass and total growing season NDVI at three latitudes.

in which $\mathrm{i}$ corresponds to the seven samples. The set of restrictions that equalizes the values of $\alpha$ is tested with a test statistic $(\omega)$, which is given by Eq. (5),

$\omega=\frac{\left(\mathrm{RSS}_{\mathrm{R}}-\mathrm{RSS}_{\mathrm{U}}\right) / \mathrm{S}}{\mathrm{RSS}_{U} /(\mathrm{T}-\mathrm{K})}$

in which $T$ is the number of observations (167), $\mathrm{K}$ is the number of regressors in the unrestricted equation, $s$ is one less than number of coefficients restricted to be equal (in this case, 6$), \mathrm{RSS}_{\mathrm{R}}$ is the residual sum of squares from the restricted model (Eq. (3)) and $\mathrm{RSS}_{U}$ is the residual sum of squares from the unrestricted version of equation ( $\mathrm{Eq}$. (4)). The test statistic $(\omega)$ is distributed as an $F$ with $s$ and $(T-K)$ degrees of freedom in the numerator and denominator, respectively. If $\omega$ exceeds the critical value, this result indicates that the residual sum of squares for the restricted model increases in a manner that is statistically significant at the relevant level of significance relative to the residual sum of squares for the unrestricted model, in which case we reject the null hypothesis that the intercepts are equal across the seven samples. The results indicate that we strongly reject the set of restrictions that equalize the values of $\alpha$ $(F(6,158)=7.53, p<0.0001)$.
Although the value of $\alpha$ varies by sample, this will have little effect on the estimate for the carbon sink. For the purpose of evaluating our ability to use the regression results from Eq. (3) to calculate the change in carbon storages, we test whether the relation between NDVI and biomass varies among the seven samples. We compare a restricted model (Eq. (4)), in which $\alpha$ varies across the seven samples, against an unrestricted version of the model (Eq. (6)), in which both $\alpha$ and $\beta$ vary across the seven samples,

$$
\begin{aligned}
1 / \text { Biomass }= & \sum_{i=1}^{7} \alpha_{i}+\sum_{i=1}^{7} \beta_{i}\left[(1 / \text { NDVI }) / \text { Latitude }^{2}\right] \\
& +\gamma \text { L atitude. }
\end{aligned}
$$

The results indicate that we reject the null hypothesis that the $\beta^{\prime} \mathrm{s}$ are the same across the seven samples $(F(6,151)=$ $2.59, p>0.03$ ), but much less strongly than we rejected the previous restriction. This result implies that the values for $\beta$ vary among nations. To assess this variation, we estimate Eq. (3) seven times with observations for an individual nation and/or period and test the null hypothesis $\beta=0$. The results indicate that there is a statistically meaningful relation between biomass and NDVI in nearly every nation 
and sample period (Table 1). For Finland, the relation is significant at the $p<0.1$ level, but not at the $p<0.05$ level. This result is not surprising given the small sample from Finland (the regression equation estimated from the Finnish data has only $5 \mathrm{df}$ ). For the USA, there is no statistically meaningful relation between NDVI and biomass. This failure is due to a single observation. If we remove this observation and reestimate Eq. (3), there is a statistically meaningful relation between NDVI and biomass $(p<0.01)$. Together, these results indicate that there is a statistically significant correlation between NDVI and biomass within nations.

Variations in $\beta$ among nations could affect our estimate for the change in the carbon pool if the differences are systematically associated with NDVI or latitude. Therefore, we evaluate the stability of the relation between biomass and NDVI statistically. One way to evaluate the relation is to estimate Eq. (3) with subsamples that include values of NDVI equal to or greater than a pre-defined threshold. For this subsample, we can evaluate whether there is a relation between biomass and NDVI by testing the null hypothesis $\beta=0$. Rejecting this null hypothesis would indicate that there is a relation between biomass and NDVI within the range of values for NDVI that is defined by the threshold. To explore this possibility, we estimate the relation between biomass and NDVI at every possible threshold for NDVI between 47 and 127 (the minimum and maximum values are chosen so that there are enough degrees of freedom to do the statistical tests). To do so, we estimate Eq. (3) with a subsample that includes observations with a value for NDVI of 127 or greater and progressively lower the threshold by one unit. Line (4) in Fig. 7a shows the significance level of the tstatistic for the test $\beta=0$. A value above either line (3) or line (2) indicates that $\beta$ is not statistically different from zero at threshold of $p<0.05$ or $p<0.1$ (i.e. there is no relation between NDVI and biomass). Line (4) moves above line (3) when the regression subsample includes values of NDV I equal to or greater than 113. At this point, the regression sample has less than $23 \mathrm{df}$ (line 1 ), which reduces the reliability of the statistical estimation. These results indicate

Table 1

Regression results for the total biomass Eq. (3) with data from an individual nation and period

\begin{tabular}{lrrll}
\hline Countries & $\beta_{1}$ & $\begin{array}{l}\text { Standard } \\
\text { error }\end{array}$ & t-Statistic & $\begin{array}{l}\text { D egrees of } \\
\text { freedom }\end{array}$ \\
\hline $\begin{array}{l}\text { Sweden } \\
\quad \text { 1982-1986 }\end{array}$ & 2836 & 968 & $2.93(p<0.004)$ & 18 \\
$\begin{array}{l}\text { Sweden } \\
\quad 2743\end{array}$ & 951 & $2.89(p<0.004)$ & 18 \\
$\quad$ No95- 1999 & & & & \\
Norway & 9858 & 2038 & $4.84(p<0.0001)$ & 14 \\
Finland & 2793 & 1536 & $1.82(p<0.07)$ & 5 \\
Canada & 1631 & 382 & $4.27(p<0.0001)$ & 8 \\
Russia & 8315 & 2664 & $3.12(p<0.002)$ & 54 \\
USA & 747 & 562 & $1.33(p<0.19)$ & 29 \\
USA * & 1371 & 527 & $2.60(p<0.01)$ & 28
\end{tabular}

* Result for US when one outlier is removed. that there is a relation between NDV I and biomass for nearly all values for NDVI.

A nother important issue is whether the relation between biomass and NDVI for values above the threshold is the same as the relation for values below the threshold. We evaluate this question by defining a dummy variable (DUM) that is equal to 1 for values of NDVI above a predefined threshold and equal to zero for values of NDVI equal to or below that threshold. We use this dummy variable to modify Eq. (3) as follows

$$
\begin{aligned}
& 1 / \text { Biomass }=\alpha_{1}+\alpha_{2} \text { DUM }+\beta_{1}\left[(1 / \text { NDVI }) / \text { L atitude }^{2}\right] \\
& +\beta_{2} \text { DUM }\left[(1 / \mathrm{NDVI}) / \mathrm{L}^{\text {atitude }}{ }^{2}\right]+\gamma \text { Latitude. }
\end{aligned}
$$

The DUM variables allow the relation between NDVI and biomass to change at a threshold. That is, if the regression coefficient $\alpha_{2}$ DUM is statistically significant, such a result indicates that the intercept for the relation between NDVI and biomass is $\alpha_{1}$ for values of NDVI equal to or less than threshold and $\alpha_{1}+\alpha_{2}$ for values of NDVI greater than the threshold. Similarly, if the regression coefficient $\beta_{2}$ DUM is significant, such a result indicates that the relation between biomass and NDVI is $\beta_{1}$ for values of NDVI equal to or less than the threshold and $\beta_{1}+\beta_{2}$ for values of NDVI greater than the threshold.

We can test whether the DUM variables in Eq. (7) are statistically significant with the $\omega$-statistic (Eq. (5)). But unlike our previous use, the $\omega$-statistic cannot be evaluated against the standard $F$ distribution. The standard $F$ distribution will overstate the significance of the $\omega$-statistic, because we evaluate subsamples for all potential NDVI thresholds between 49 and 127 without a priori theory as to the NDVI threshold at which the regression coefficients change (Christiano, 1992). The lack of an a priori threshold affects interpretation as follows. U sing Eq. (7), we test 80 thresholds. Random chance implies that 4 of the $80 \omega$ statistics will exceed the $p<0.05$ critical value for the $F$ distribution. This would cause us to argue that the regression coefficients change between subsamples.

To account for the repeated sampling (and the uneven distribution of observations), we simulate the distribution of the $\omega$-statistic that is unique to $\mathrm{Eq}$. (7) using M onte Carlo techniques (Christiano, 1992). First, we generate 1000 experimental data sets. Each data set is generated using the following equation

$$
\begin{aligned}
1 / \text { Biomass }= & \alpha+\beta\left[(1 / \text { NDVI }) / \text { L atitude }^{2}\right] \\
& +\gamma \text { Latitude }+\mu,
\end{aligned}
$$

in which $\alpha, \beta$ and $\gamma$ are the values estimated from the full sample. The 167 values of $\mu$ for each data set are generated by drawing randomly from a normal distribution with a mean value of zero and a standard error of 0.004 , which is the standard error for the regression equation estimated from the full sample. The regression coefficients remain constant 

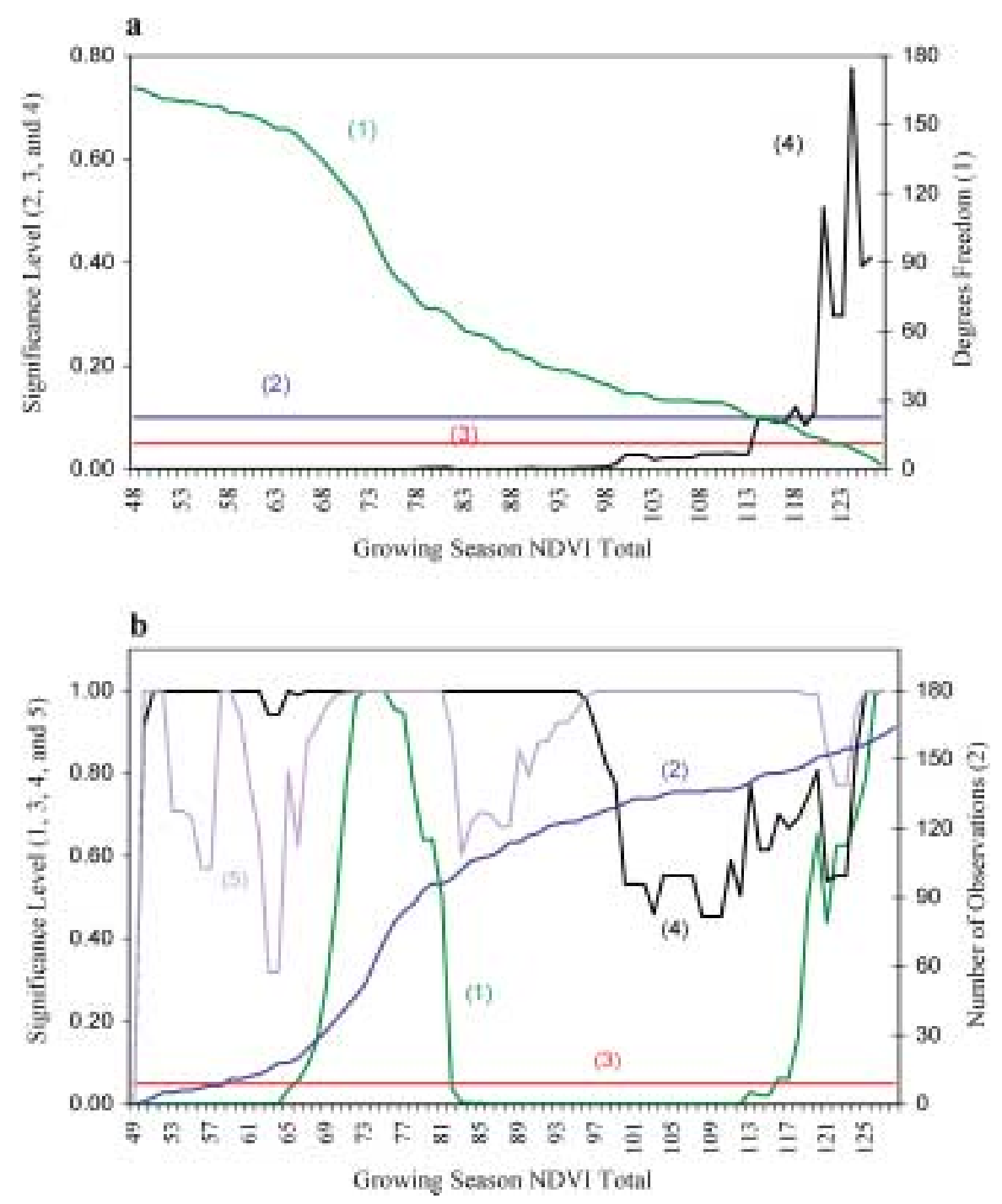

Fig. 7. (a) The relation between NDVI and biomass for samples defined by NDVI. Line (4) gives the significance level for thet-statistic associated with $\beta$ (Eq. (3)), estimated with data that include values of NDVI equal to or greater than the value given on the $x$-axis. The degrees of freedom in these regressions are given by line (1). Lines (2) and (3) represent the significance level at the $p<0.05$ and $p<0.10$ thresholds. (b) The stability of the relation between NDV I and biomass for samples defined by NDVI. Line (5) or (4) tests whether the slope ( $\beta_{1}$ DUM in Eq. (7)) or the intercept $\left(\alpha_{1}\right.$ DUM in Eq. (7)) differs between samples above and below a given threshold for NDVI, respectively. Line (1) tests whether the intercept and slope ( $\alpha_{1} D U M$ and $\beta_{1} D U M$ in Eq. (7)) differ between samples above and below a given threshold for NDVI. Line (2) represents the number of observations below a given level of NDVI. Line (3) represents the $p<0.05$ significance level.

to ensure consistency with the null hypothesis of the testthere is no change in the value of $\alpha$ and/or $\beta$ at any NDVI threshold. Each experimental data set is estimated using Eq. (7) with each threshold between 49 and 127. The largest $\omega$ statistic from the analysis of each experimental data set (regardless of the threshold it is associated with) is saved. These thousand values are ranked in descending order by size, such that the value at position 50 represents the $p<0.05$ threshold. That is, there is less than a $5 \%$ chance of generating a value for $\omega$ that is equal to or greater than this value if $\mathrm{Eq}$. (7) is searched randomly over all possible breakpoints.

The results indicate that $\mathrm{Eq}$. (3) describes the relation between biomass and NDVI over a wide range of values for
NDVI. A s indicated by line (5), we cannot reject the null hypothesis that the value for $\beta_{2} \mathrm{DUM}$ in $\mathrm{Eq}$. (7) is zero for nearly every value for the $0 / 1$ threshold (except for a threshold of 49 , for which the dummy variable has only $1 \mathrm{df}$ ). Line (4) indicates that we cannot reject the null hypothesis that $\alpha_{2}$ DUM is equal to zero for all NDVI thresholds. As indicated by line (1), we are unable to reject the null hypothesis that both $\alpha_{2} D U M$ and $\beta_{2} D U M$ are zero for thresholds above 67 and below 80 . This range generates subsamples that are approximately equal, which generate the most reliable results. As indicated by line (2), about $25 \%$ of the sample has a value for NDVI below 70 while about $40 \%$ of the observations have a value for NDVI above 80 . Together, these results indicate that the relation between 
NDVI and biomass is stable over a wide range of subsamples.

\subsection{The effect of latitude on the relation between NDVI and biomass}

A Iternatively, the relation between NDVI and biomass may vary over latitude. We can explore the effect of latitude on the relation betw een NDVI and biomass by estimating $\mathrm{Eq}$. (3) with subsamples that are defined by latitude (rather than by NDVI). The data used to estimate Eq. (3) include observations between $29^{\circ} \mathrm{N}$ and $69^{\circ} \mathrm{N}$. To see if there is a relation between NDVI and biomass within latitudinal bands, we use data from these latitudinal bands to estimate $\mathrm{Eq}$. (3) and test whether $\beta$ is statistically different from zero. The first subsample includes all observations north of $67^{\circ} \mathrm{N}$, and the next subsample includes all observations north of $66^{\circ} \mathrm{N}$. We repeat this expansion of the subsample until all observations are included. We also repeat this sampling starting with observations from low latitudes, such that the first subsample includes observations from $29^{\circ} \mathrm{N}$ to $31^{\circ} \mathrm{N}$, the second from $29^{\circ} \mathrm{N}$ to $32^{\circ} \mathrm{N}$ and so on. Regardless of the latitude that is used to truncate the subsample, we strongly reject $(p<0.01$ ) the null hypothesis that $\beta$ is equal to zero. The consistent rejection of this null hypothesis indicates that there is a statistically meaningful relation between NDV I and biomass, regardless of latitude.

3.4. Temporal and spatial relations between NDVI and biomass

To explore whether the spatial relation between biomass and NDVI is different from the temporal variation between biomass and NDVI, we use observations for Sweden to estimate the following equation,

$$
\begin{aligned}
1 / \text { Biomass }= & \alpha_{1}+\alpha_{2} \text { DUM } 8286 \\
& +\beta_{1}\left[(1 / \text { NDVI }) / \text { Latitude }^{2}\right] \\
& +\beta_{2} \text { DUM } 8286\left[(1 / \text { NDV }) / \text { Latitude }^{2}\right] \\
& +\gamma \text { Latitude },
\end{aligned}
$$

in which DUM 8286 is a dummy variable that is equal to 1 for observations from the $1982-1986$ period and is equal to 0 for observations from the 1995- 1999 period. If the spatial relation between biomass and NDVI during the 1982- 1986 and 1995-1999 periods is different from the temporal relation between biomass and NDVI between these two periods, $\alpha_{2} \mathrm{DUM}$ and/or $\beta_{2} \mathrm{DUM}$ will not be equal to zero. Conversely, if the spatial relation between biomass and NDVI during the 1982-1986 and 1995-1999 periods is the same as the temporal relation between NDVI and biomass between these two periods, $\alpha_{2} \mathrm{DUM}$ and/or $\beta_{2} \mathrm{DUM}$ will be zero.
We test whether $\alpha_{2}$ DUM and/or $\beta_{2}$ DUM are equal to zero with the $\omega$-statistic that is evaluated against the standard $F$ distribution. Results indicate that we cannot reject the null hypothesis that $\alpha_{2} \mathrm{DUM}$ is equal to zero $(F(1,36)=0.005$, $p<0.95), \quad \beta_{2} D \cup M$ is equal to zero $(F(1,36)=0.01$, $\mathrm{p}<0.91)$, or $\alpha_{2} \mathrm{DUM}$ and $\beta_{2} \mathrm{DUM}$ are equal to zero $(F(2,36)=0.07, p<0.94)$. Together, these results indicate that the spatial relation between biomass and NDVI is not statistically different from the temporal relation between biomass and NDVI.

\section{Biomass estimates}

\subsection{Pattern of woody biomass sinks and pools}

Seasonal totals for NDVI are obtained by matching provincial estimates of forest area from inventory data and those from a high-resolution $(1 \mathrm{~km})$ satellite vegetation map (Hansen et al., 2000) in a geographical information system. A nnual data are averaged over two 5-year periods, 1982-1986 and 1995-1999, that correspond to the start and end of the satellite records. To calculate the change in carbon storage between these periods, the period averages are subtracted from each other. Fig. 8a shows the difference of the growing season NDVI totals between two time periods for all vegetated regions. Growing season is defined as the period when composite (15-day) NDVI values are greater than 0.1. The forest fraction, expressed as the fraction of each quarter degree pixel area under forest land covers (broad leaf forests, needle leaf forests, mixed forests and woody savannas) (Hansen et al., 2000) (Fig. 8b), is used as a weight to convert NDVI totals to biomass in each pixel.

B ecause of their high spatial resolution relative to inventory measurements, biomass estimates from satellite data provide spatial detail on the carbon pool and the location and magnitude of changes. The spatial picture of pixel level changes in the biomass pool shown in Fig. 9a depicts carbon gains in excess of 0.3 ton $\mathrm{C} / \mathrm{ha} / \mathrm{year}$ in Eurasian boreal and $\mathrm{N}$ orth A merican temperate forests and carbon losses greater than 0.1 ton $\mathrm{C} / \mathrm{ha} / \mathrm{year}$ in some $\mathrm{Canadian}$ boreal forests. The gains in Eurasia are located over a large, broad, nearly contiguous swath of land from Sweden (about $10^{\circ} \mathrm{E}$, north of $60^{\circ} \mathrm{N}$ ), through Finland, European Russia, central Siberia to trans-B aikalia $\left(120^{\circ} \mathrm{E}\right.$, north of $\left.50^{\circ} \mathrm{N}\right)$. In N orth A merica, similar gains occur in the eastern temperate forests of the USA and in southern Ontario and Quebec below the 50th parallel. Carbon losses occur in Canada's boreal forests, from Newfoundland to Northwest territories, except for small fragments in northern Saskatchewan and Alberta, where carbon storage increases (about $110^{\circ} \mathrm{W}$ and $60^{\circ} \mathrm{N}$ ). The biomass map in Fig. 9b indicates larger pools, in ton C/ ha, in North A merica compared to Eurasia (51 vs. 39). The average pool size in Europe and the USA is larger than in Canada and Russia (54- 58 vs. 38-44). A mong European 

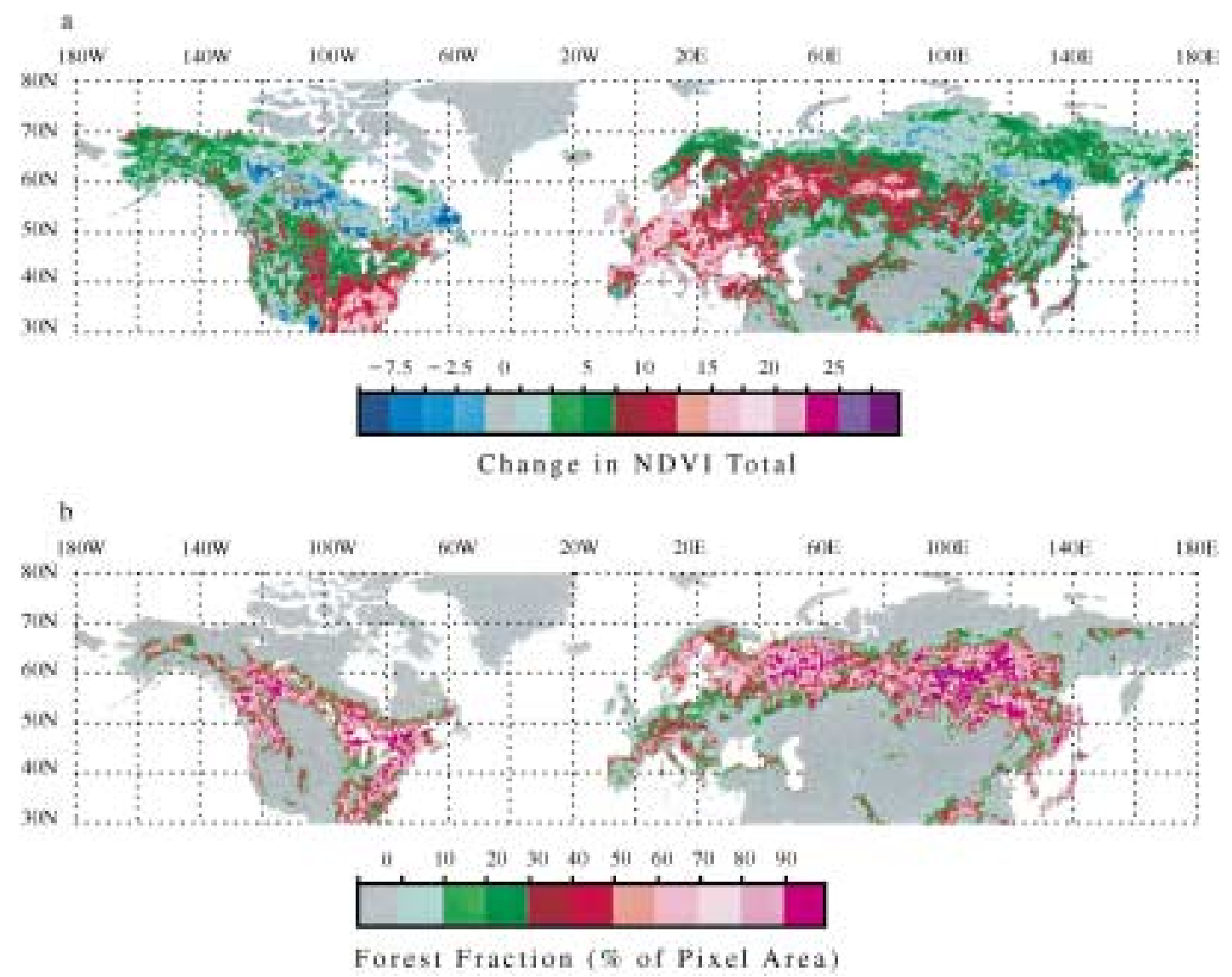

Fig. 8. (a) Difference in growing season NDVI totals between two time periods, 1995 - 1999 and 1982 - 1986, for all vegetated regions and (b) map of forest fraction defined as the fraction of each quarter degree pixel area under forest land covers.

countries, A ustria, France and Germany have relatively large pools (60,67 and 73, respectively). The estimates for Finland, Norway and Sweden are comparable to Russia (35- 40 vs. 38).

\subsection{Comparison of remote sensing and inventory estimates}

We estimate that the 1.42 billion ha of temperate and boreal forests stored $61 \pm 20 \mathrm{Gt} \mathrm{C}$ during the late 1990s (Table 2). The estimate for carbon gain during the 1980 s and $1990 \mathrm{~s}$ is $0.68 \pm 0.34 \mathrm{Gt}$ C/year. This is in the mid-range of estimates by Sedjo (1992) for the mid-1980s (0.36 Gt C/ year) and Temperate and Boreal Forest Resources A ssessment- 2000 (Liski \& K auppi, 2000) for the early and mid1990s (0.88 Gt C/year).

The sequestration rate, in ton $\mathrm{C} / \mathrm{ha} / \mathrm{year}$, is highest in Europe (0.84) and the USA (0.66), and smallest in Canada and China (0.27-0.31), with intermediate values for Russia (0.44). As a result, sequestration rates in Eurasia and North A merica $(0.47-0.49)$ are similar. This implies that nearly $70 \%$ of the sink is in Eurasia (0.47 Gt C/year), which is consistent with its forest area but is disproportionably large relative to its pool size (Table 2). Estimates for the carbon pool and sink in the woody biomass of temperate and boreal forests in individual nations are given in Table 3.

We evaluate the uncertainties in the satellite estimates for the biomass pool and changes by comparing them to national, provincial and state estimates (Fig. 10 and A ppen$\operatorname{dix} A$ ). Panel (a) compares estimates of the above-stump biomass carbon pool in 46 states of the USA (Cost, 1990), 11 provinces of Canada (Penner, Power, M uhairwe, Tellier, \& Wang, 1997) and total biomass pool in 37 Eurasian countries (Liski \& Kauppi, 2000). It also shows inventory biomass estimates for 10 US states for which data are available from two time periods (FIA, 2000). The inventory estimates shown here are not used to estimate the regression model. The remote sensing estimates are calculated by simulating the regression models with pixel-level cumulative growing season NDVI data that are averaged over the 5 years prior to the inventory dates, and using the highresolution satellite vegetation map to identify forest pixels (Hansen et al., 2000). Both sets of biomass estimates are converted to carbon by multiplying by 0.5 , a standard factor for converting woody biomass to carbon. Estimates for Japan are divided by 2 to correspond with the axes. Panel (b) compares changes in the woody biomass carbon pool in 22 provinces of Sweden, 9 states of the USA (FIA, 2000) 


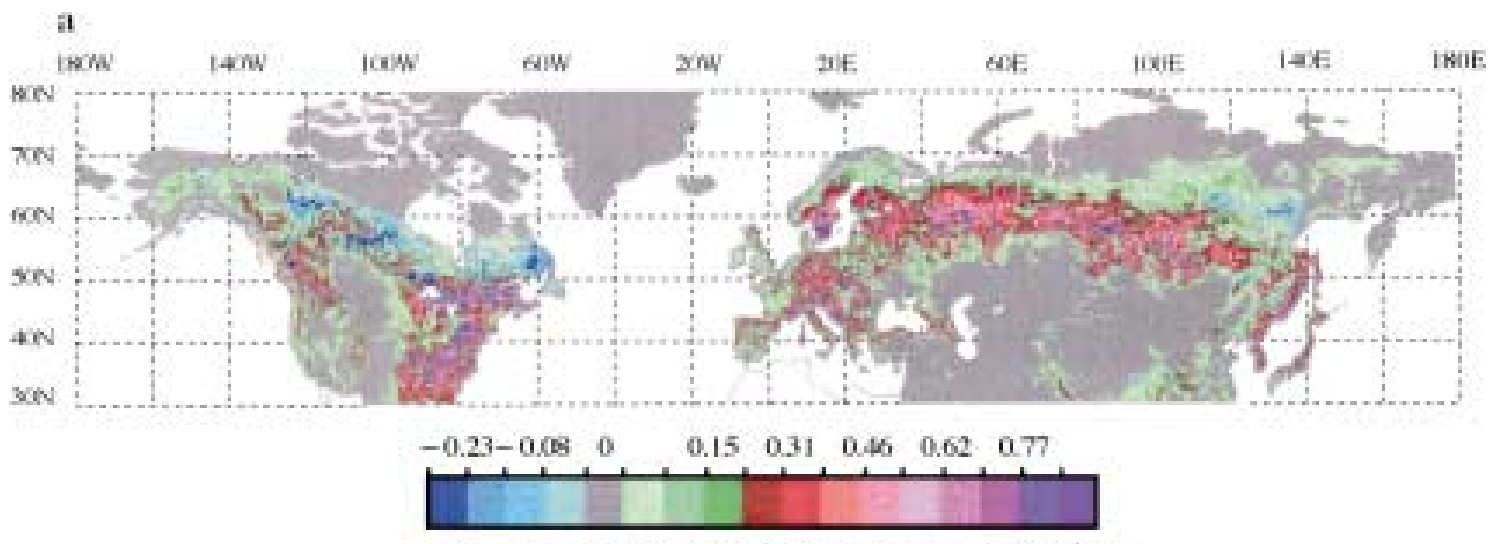

Changes in Carbon Pool (tons $\mathrm{C} / \mathrm{ha} / \mathrm{yr}$ )

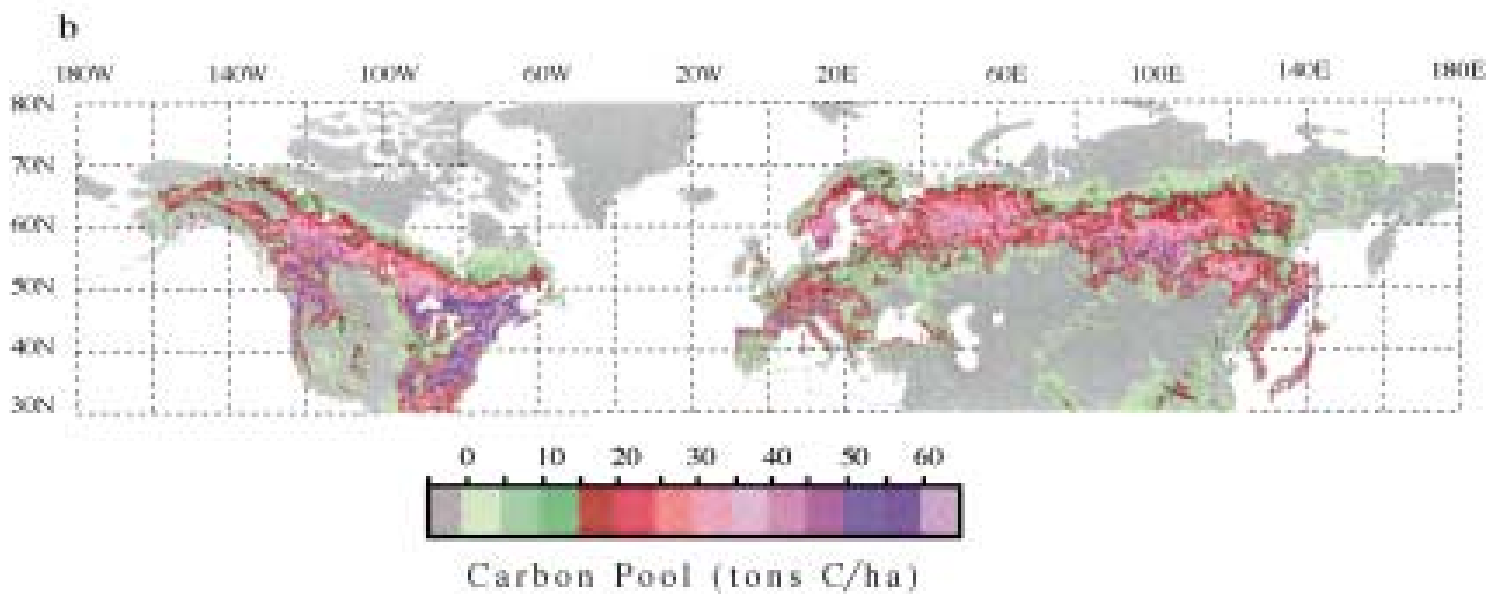

Fig. 9. Spatial detail of changes in the woody biomass carbon pool of northern forests between late 1990s and early 1980s (a) and pool size during late 1990s (b).

and 37 Eurasian countries (Liski \& Kauppi, 2000). The Swedish data measure changes in two successive inventories (1993- 1997 and 1982-86) of stem wood volume that

Table 2

Remote sensing estimates of carbon pool (1995-1999) and sink in total woody biomass of temperate and boreal forests in N orth A merica and Eurasia

\begin{tabular}{|c|c|c|c|c|}
\hline Country & $\begin{array}{l}\text { Average } \\
\text { pool } \\
\text { (tons/ha) }\end{array}$ & $\begin{array}{l}\text { Carbon } \\
\text { pool } \\
(\mathrm{Gt} \mathrm{C})\end{array}$ & $\begin{array}{l}\text { Carbon } \\
\text { sink } \\
\text { (Gt C/year) }\end{array}$ & $\begin{array}{l}\text { Forest } \\
\text { area } \\
\text { (M ha) }\end{array}$ \\
\hline Canada & 44.09 & 10.56 & 0.07312 & 239.5 \\
\hline USA & 57.91 & 12.48 & 0.14153 & 215.5 \\
\hline N orth A merica & 50.64 & 23.04 & 0.21465 & 455.0 \\
\hline China & 25.77 & 3.68 & 0.03862 & 142.6 \\
\hline Finland & 34.88 & 0.60 & 0.00556 & 17.2 \\
\hline Japan & 47.35 & 0.90 & 0.01192 & 19.0 \\
\hline Russia & 37.98 & 24.39 & 0.28359 & 642.2 \\
\hline Sweden & 39.86 & 1.06 & 0.01386 & 26.5 \\
\hline Other ${ }^{\dagger}$ & 59.40 & 7.05 & 0.11617 & 117.4 \\
\hline Eurasia & 39.99 & 37.68 & 0.46972 & 964.9 \\
\hline Total & 42.91 & 60.72 & 0.68437 & 1419.9 \\
\hline
\end{tabular}

\footnotetext{
${ }^{\dagger}$ A Ibania, A rmenia, A ustria, A zerbaijan, B elarus, B elgium, B osnia and Herzegovina, Bulgaria, Croatia, Cyprus, Czech Republic, Denmark, Estonia, France, Georgia, Germany, Greece, Hungary, Italy, Kazakhstan, Kyrgyzstan, Latvia, Lithuania, Netherlands, Norway, Poland, Portugal, Romania, Slovakia, Slovenia, Spain, Switzerland, Tajikistan, Turkey, Turkmenistan, United Kingdom, Ukraine, U zbekistan.
}

we convert to woody biomass in carbon units and divide by the time interval (11 years), as we did for the nine states of the USA. The Eurasian data are for the early to mid-1990s period. Only the Swedish data were used to estimate the regression model. The remote sensing estimates for changes in carbon storage are the differences in the predicted carbon pool for the respective time periods and expressed on an annual basis.

The average absolute difference between remote sensing and inventory estimates is 10.4 ton $\mathrm{C} /$ ha for above-stump biomass, 16.1 ton C/ha for total biomass, and 0.33 ton C/ha/ year for changes in pool size, or $27 \%, 33 \%$ and $50 \%$ of the mean inventory estimates, respectively (Fig. 10a). The national inventory sink estimates, in Fig. 10b (Liski \& K auppi, 2000), are derived from wood volume increment and loss data (natural and fellings), unlike remote sensing estimates, which are biomass differences between two time periods. The comparability of the two estimates is thus noteworthy. We also evaluate changes in the carbon pool generated by uncertainty in the biomass- NDVI relation alone. The results indicate that the standard error for our estimates of change is one to two orders of magnitude smaller than the average change, 0.48 ton $\mathrm{C} / \mathrm{ha}$ /year, as discussed below.

If the estimates for biomass generated by the remote sensing/statistical methodology are unbiased relative to 
Table 3

Estimates of the carbon pool and sink in the woody biomass of temperate and boreal forests by country

\begin{tabular}{|c|c|c|c|}
\hline Country & $\begin{array}{l}\text { Carbon pool } \\
(\mathrm{Tg} \mathrm{C})\end{array}$ & $\begin{array}{l}\text { Carbon sink } \\
\text { ( } \mathrm{Tg} \mathrm{C} / \text { year) }\end{array}$ & $\begin{array}{l}\text { Forest area } \\
\text { (million ha) }\end{array}$ \\
\hline Albania & 28.274 & 0.558 & 0.532 \\
\hline A rmenia & 14.386 & 0.426 & 0.328 \\
\hline A ustria & 263.196 & 4.039 & 4.359 \\
\hline A zerbaijan & 43.706 & 1.287 & 0.841 \\
\hline Belgium & 34.708 & 0.226 & 0.471 \\
\hline Bosnia & 178.236 & 3.297 & 2.516 \\
\hline Bulgaria & 160.584 & 4.095 & 2.531 \\
\hline Belarus & 171.241 & 3.339 & 3.366 \\
\hline Canada & 10560 & 73.123 & 239.500 \\
\hline China & 3675.311 & 38.62 & 142.600 \\
\hline Croatia & 127.828 & 1.982 & 1.787 \\
\hline Czech & 154.151 & 3.245 & 2.971 \\
\hline Denmark & 6.29 & 0.133 & 0.106 \\
\hline Estonia & 109.006 & 1.234 & 2.294 \\
\hline Finland & 601.369 & 5.558 & 17.243 \\
\hline France & 1136.249 & 8.518 & 15.666 \\
\hline Georgia & 142.365 & 3.234 & 2.384 \\
\hline Germany & 622.256 & 12.262 & 9.354 \\
\hline Greece & 111.421 & 2.72 & 1.981 \\
\hline Hungary & 47.017 & 1.02 & 0.746 \\
\hline Italy & 585.941 & 10.835 & 8.489 \\
\hline Japan & 897.967 & 11.915 & 18.965 \\
\hline K azakhstan & 117.732 & 2.025 & 3.087 \\
\hline K yrgyzstan & 16.658 & 0.385 & 0.658 \\
\hline Latvia & 176.342 & 2.406 & 3.543 \\
\hline Lithuania & 87.933 & 1.235 & 1.819 \\
\hline M acedonia & 41.205 & 0.837 & 0.640 \\
\hline N etherlands & 10.847 & 0.16 & 0.157 \\
\hline Norway & 259.108 & 2.782 & 6.958 \\
\hline Poland & 322.26 & 6.946 & 6.361 \\
\hline Portugal & 122.716 & 2.57 & 2.032 \\
\hline Romania & 355.547 & 7.926 & 5.378 \\
\hline Russia & 24393.805 & 283.589 & 642.221 \\
\hline Slovakia & 138.065 & 3.427 & 2.077 \\
\hline Slovenia & 89.37 & 1.668 & 1.219 \\
\hline Spain & 588.747 & 7.344 & 10.424 \\
\hline Sweden & 1054.516 & 13.859 & 26.455 \\
\hline Switzerland & 107.971 & 1.247 & 1.734 \\
\hline Turkey & 296.043 & 6.91 & 5.454 \\
\hline Turkmenistan & 0.18 & 0.004 & 0.016 \\
\hline United K ingdom & 204.827 & 4.353 & 1.864 \\
\hline Ukraine & 132.258 & 1.325 & 3.702 \\
\hline USA & 12480 & 141.528 & 215.500 \\
\hline Uzbekistan & 0.289 & 0.001 & 0.030 \\
\hline
\end{tabular}

those generated from inventory data, the data in Fig. 10a and $b$ will lie al ong the $45^{\circ}$ line. By definition, this $45^{\circ}$ line has an intercept of zero and a slope of 1 . To test whether this $45^{\circ}$ line describes the relation between the biomass estimates generated by remote sensing/statistical methodology and those generated from the inventory data, we estimate the following equation,

Inventory $=\alpha+\beta$ Remote Sensing $+\mu$,

in which Inventory is the estimate for biomass from forest inventories in Fig. 10a or b, Remote Sensing is the remote sensing biomass estimate generated in Fig. 10a or b, $\alpha$ and $\beta$ are regression coefficients, and $\mu$ is a normally distributed random error term.

To test the null hypothesis that the intercept $(\alpha)$ is equal to zero, we use a t-statistic. This test statistic will reject the null hypothesis if its value exceeds the value associated with the $p<0.05$ threshold. Failure to exceed this threshold indicates that the intercept is not statistically different than zero. To test the null hypothesis that $\beta$ equals 1.0 , we use the $\omega$-statistic (Eq. (5)). This test statistic will reject the null hypothesis if imposing a value of 1 on $\beta$ causes the residual sum of squares for Eq. (10) to increase in a statistically significant fashion relative to the version of $\mathrm{Eq}$. (10) in which $\beta$ is allowed to assume the value that minimizes the residual sum of squares. Failing to exceed this threshold would indicate that $\beta$ is not statistically different from one. Lastly, both of these hypotheses $(\alpha=0, \beta=1)$ can be tested

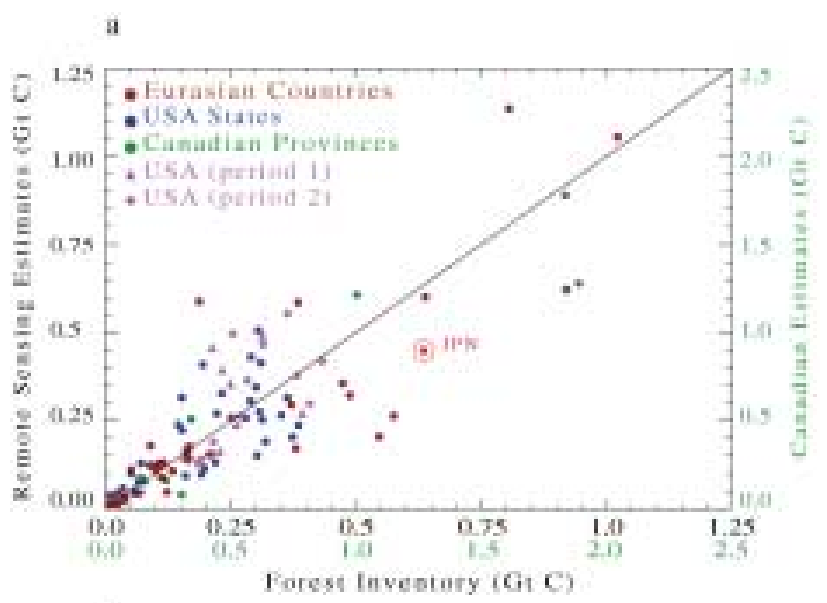

b

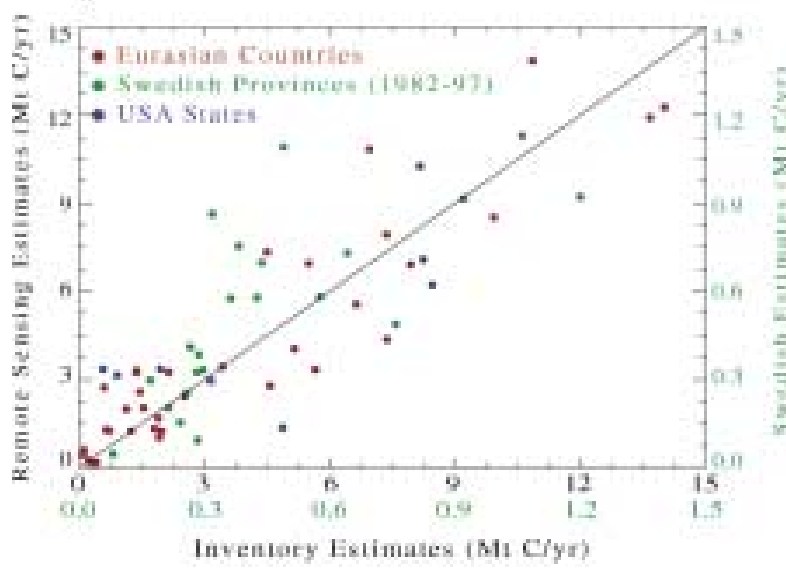

Fig. 10. Comparison of remote sensing and inventory estimates of the biomass carbon pool (a) and its rate of change (b). In both panels, we show estimates at the provincial, state and national level, rather than on per unit forest area basis, to include uncertainties associated with differences in respective estimates of forest area. The scales for Canadian estimates of carbon pools are larger than the estimates for the other countries, because the provincial forest area in Canada is large. Similarly, Swedish estimates of changes in carbon pools have smaller scales because of smaller forest area in the provinces of Sweden. 
jointly with the $\omega$-statistic. This test statistic will reject this null hypothesis if imposing the restrictions on $\alpha$ and $\beta$ causes the residual sum of squares for Eq. (10) to increase in a statistically significant fashion relative to the version of Eq. (10) in which $\alpha$ and $\beta$ are allowed to assume the values that minimize the residual sum of squares. Failing to exceed this threshold would indicate that $\alpha$ is not statistically different from zero and $\beta$ is not statistically different from 1.0.

Results indicate that we fail to reject any of these hypotheses. The intercept of a line fit to data in Fig. 10a is not statistically different from zero $(t=0.83, p<0.42)$. Similarly, the slope of the line is not statistically different from $1.0(F(1,112)=0.40, p<0.53)$. Finally, we cannot reject the null hypothesis $(\alpha=0, \beta=1)$ for the data in Fig. 10a $(F(2,112)=0.35, p<0.71)$. Similar results are obtained for the data in Fig. 10b. The intercept of a line fit to data in Fig. $10 \mathrm{~b}$ is not statistically different from zero $(t=0.05$, $p<0.97)$ nor is the slope of the line statistically different from $1.0(F(1,66)=1.28, p<0.27)$. Finally, we cannot reject the null hypothesis $(\alpha=0, \beta=1)$ for the data in Fig. 10b $(F(2,66)=1.07, p<0.35)$. Together, these results indicate that the biomass estimates generated by the remote sensing/ statistical methodology are unbiased relative to the biomass estimates generated from inventory data.

\subsection{The effect of uncertainty in the biomass- NDVI relation on the carbon sink estimate}

We estimate the effect of uncertainty in the statistical relation between biomass and NDVI on the estimate for the carbon sink by running a M onte Carlo simulation. Ideally, this Monte Carlo experiment would be simulated with the entire data set. For each pixel and period in North A merica and Eurasia, we would use the values of NDVI to calculate a value for biomass that includes an error. This error would be determined by the standard error for our estimate of biomass, which can be derived from the regression results. This process would be repeated a thousand times to generate a confidence interval for our point estimate of the carbon sink. Unfortunately, this process is not computationally feasible, because the North A merican and Eurasian data set includes tens of millions of pixels.

To avoid these difficulties, we evaluate the effect of uncertainty in biomass-NDVI equation on our estimates for the size of the sink by running a $M$ onte Carlo experiment for a simulated landscape in which NDVI does not change. To do so, we create a hypothetical landscape of 10,000 pixels $\left(640,000 \mathrm{~km}^{2}\right)$ where NDVI is identical for each pixel for both periods. We use statistical techniques to calculate the standard error associated with the point estimate for biomass that is generated by the biomass- NDV I equation (Eq. (3)). This standard error increases as the values for NDVI and latitude move away from the sample mean (83 and $54^{\circ}$, respectively). This standard error is multiplied by a normally distributed random variable that has a mean value of zero and a variance of 1 . The resultant estimate for the regression error is added to the point estimate to calculate a value of biomass for each pixel. This process is repeated for each pixel to generate a second value for biomass for each pixel. These two values are subtracted from each other and divided by two to calculate each pixel's change in carbon pool. These values are summed over the 10,000 pixels to calculate the total change in the carbon pool in the hypothetical landscape. The total is divided by 10,000 to calculate the mean change in carbon storage per pixel. This process is repeated 1000 times. We use these thousand observations to calculate a mean (and standard error) change in the carbon pool for the $640,000 \mathrm{~km}^{2}$ hypothetical landscape where NDVI does not change.

The results (Table 4) indicate that the mean estimate for the per pixel change in the carbon pool is statistically indistinguishable from zero and that the standard error of this mean is one or two orders of magnitude smaller than the positive per ha change in carbon pool (sink) reported in the previous section ( 0.48 ton $\mathrm{C} / \mathrm{ha} / \mathrm{year}$ ). The small size of the standard error relative to the per pixel carbon sink does not vary greatly if we change the values for latitude and/or NDVI that are associated with the hypothetical $640,000-\mathrm{km}^{2}$ landscape (the size of standard error decreases as we increase the number of pixels included in the $M$ onte Carlo simulation). The generality of this result indicates that it is highly unlikely that the size the carbon sink reported in the text is a statistical artifact of the uncertainty in the statistical relation between biomass and NDVI.

\subsection{Comparison of estimates for Canada, China, Russia and the USA}

Four large countries, Canada, China, Russia and the USA, contain $84 \%$ of the pool, $78 \%$ of the sink and $87 \%$ of the forest area. B ecause of their importance, we compare remote sensing estimates for these four countries with other estimates. These comparisons are difficult because of differences in the definition of forest areas, periods for which the estimates are valid and large uncertainties associated with all estimates. The TBFRA-2000 estimates generally are for the mid-1990s. O ur sink estimate for the USA (0.142 Gt C/year) is comparable to the TBFRA-2000 estimate $(0.166 \mathrm{Gt} \mathrm{C}$ / year). It is greater than estimates for the 1980 s, from both

Table 4

M onte Carlo simulation results to evaluate the change in carbon storage that is generated by the uncertainty in biomass- NDVI equation

\begin{tabular}{llll}
\hline Latitude & NDVI & & \\
\cline { 2 - 4 } & 40 & 80 & 120 \\
\hline $30^{\circ}$ & $2.57 \mathrm{e}-04(0.00246)$ & $0.000701(0.00671)$ & $0.00166(0.01582)$ \\
$50^{\circ}$ & $4.85 \mathrm{e}-04(0.00468)$ & $0.000799(0.00772)$ & $0.00521(0.04979)$ \\
$70^{\circ}$ & $1.89 \mathrm{e}-04(0.00184)$ & $0.000903(0.00871)$ & $0.00205(0.01962)$ \\
\hline
\end{tabular}

The number is mean per pixel changes in carbon pool (tons C/year/pixel); the values in parenthesis are the standard errors for this estimate. NDVI here refers to total growing season NDVI. 
inventory $(0.063 \mathrm{Gt} \mathrm{C/year} \mathrm{by} \mathrm{Turner} \mathrm{et} \mathrm{al.,} 1995$ and 0.098 Gt C/year by Birdsey \& Heath, 1995) and land-use change studies ( $0.02 \mathrm{Gt} \mathrm{C/year} \mathrm{by} \mathrm{Houghton,} \mathrm{Hackler,} \mathrm{\&} \mathrm{L} \mathrm{aw} \mathrm{rence,}$ 1999). O ur estimates of pool size ( $12.5 \mathrm{GtC}$ ) and forest area (215 M ha) for the late 1990s are comparable to those published by TBFRA-2000 (13.85 Gt C, and $217 \mathrm{Mha,}$ respectively). Since the 1970 s, Canadian forests have been disturbed by fires and insect damage (K urz \& A pps, 1999), which is consistent with the loss of carbon in Fig. 9a. Our sink estimate, $0.073 \mathrm{Gt} \mathrm{C/year,} \mathrm{is} \mathrm{similar} \mathrm{to} \mathrm{estimates}$ reported by TBFRA-2000 (0.093 Gt C/year) and the Canadian Forest Service (about 0.085 Gt C/year for the 19811991 period). Our estimate for the total terrestrial sink in Canada between 1980 and 1996 is slightly greater than that inferred by Chen, Chen, Liu, Cihlar and Gray (2000) $(0.053$ Gt C/year). Our estimates for pool size (10.6 Gt C) and forest area (239 M ha) for the late 1990s al so are comparable to the TBFRA -2000 estimates ( $11.9 \mathrm{Gt} \mathrm{C}$ and $244 \mathrm{M} \mathrm{ha}$ ).

Our estimate for pool size in China (3.68 Gt C for the 1995- 1999 period) is slightly lower than the estimate by Fang et al. (2001) (4.75 Gt C for the 1994- 1998 period), and the remote sensing estimate of forest area (142.6 M ha) is slightly greater than the Fang et al. estimate (105.82 for the 1994-1998 period). These differences cause estimates of average pool sizes to differ. Our estimate (25.77 tons/ha for the 1995-1999 period) is smaller than the estimate by Fang et al. (2001) (44.75 tons/ha for the 1994-1998 period). Our sink estimate ( $0.039 \mathrm{Gt} \mathrm{C/year} \mathrm{for} \mathrm{the} \mathrm{period}$ $1982-1999$ period) is slightly greater than the Fang et al.'s estimate (0.024 Gt C/year for the 1984 - 1998 period). These differences may be caused by the large change in planted forests due to afforestation and reforestation programs from $12.74 \mathrm{M} \mathrm{ha}$ in the 1977-1981 period to $18.74 \mathrm{M}$ ha in the 1984 - 1988 period.

The remote sensing estimate of Russian forest area, 642 $M$ ha, is lower than estimates by TBFRA-2000 (2000) (816 M ha), A lexeyev and Birdsey (1998) (771 M ha) and Nilsson et al. (2000) (764 M ha). These differences may be associated with the definition of forest. Forest and other wooded land (FOWL) in the FAO statistics is equival ent to what Russia defines as "forest land", which includes "forested area" and "unforested area". "Forested area" is defined by stocking density. "U nforested area" is land where stocking density is temporarily below the forested area threshold. In 1993, "forest land" was $887 \mathrm{M} \mathrm{ha,} \mathrm{"forested} \mathrm{area"} \mathrm{was} 764 \mathrm{M} \mathrm{ha}$ and "unforested area" was $123 \mathrm{M} \mathrm{ha}$.

Estimates by A lexeyev and Birdsey (1998) and Nilsson et al. (2000) may include "forested area" only, which is not comparable to the remote sensing land cover definition of forests. These inventory estimates fluctuate. For example, the area of stocked stands ("forested area") was estimated to be $771.2 \mathrm{M}$ ha in $1988,763.5 \mathrm{M}$ ha in 1993 and $769.8 \mathrm{M}$ ha in 1998.

The low estimate for forest area that is generated by the remote sensing methodology ( $642 \mathrm{M}$ ha) may be caused by the coarse resolution of satellite data $(8 \times 8 \mathrm{~km})$. This resolution may not capture tree stands in the forest- tundra of Russia, where small lots of sparse, open larch stands with extremely low growing stock $\left(30-50 \mathrm{~m}^{3} / \mathrm{ha}\right.$ ) are located throughout the vast peatlands. In addition, Russia has about $35 \mathrm{Mha}$ of dwarf shrub communities (Betula nana and others) which are counted as forests in inventory studies. The total area of plain and mountain forest- tundra forests is about $108 \mathrm{M} \mathrm{ha}$, which may not be classified as forest land cover in remote sensing data (recent unpublished analysis of A lexeyev). There is an additional 20-30-M ha difference between remote sensing and inventory estimates. When expressed on a per ha forest area basis, the various pool estimates are comparable (38-43 tons $C / h a)$. The difference in sink estimates between remote sensing and the TBFRA 2000 is smaller ( 0.44 vs. 0.53 ; in tons $C /$ ha/year). Nilsson et al.'s estimate for the biomass sink, $0.058 \mathrm{Gt}$ C/year, is smaller than our (0.292 Gt C/year) and the TBFRA-2000 estimates ( $0.423 \mathrm{Gt} \mathrm{C/year).} \mathrm{Nilsson} \mathrm{et} \mathrm{al.} \mathrm{could} \mathrm{not} \mathrm{have}$ derived their sink estimate from data for stem wood volume data because the increment they quote $\left(816 \mathrm{M} \mathrm{m}^{3} /\right.$ year) on $760 \mathrm{M}$ ha of forested area in 1990 is comparable to TBFR A 2000 estimate of $1134 \mathrm{M} \mathrm{m}^{3} /$ year on $886 \mathrm{M}$ ha of FOWL area during the same period. If they used data for stem wood volume, the three sink estimates would be comparable on a per unit forest area basis. Alexeyev and Birdsey (1998) do not provide a sink estimate. It is not clear why the TBFRA 2000 estimate for forest area (816 M ha) is different than the remote sensing estimate, considering that the two agree well for Canada, USA and other countries.

\section{Discussion}

How robust are these results? Residual atmospheric effects and calibration errors in satellite data cannot be ruled out. Uncertainties in inventory data are country-specific and difficult to quantify (Liski \& K auppi, 2000). Simple models are used to convert wood volume and satellite greenness data to biomass. The validity of the biomass- NDVI relation at all scales is open to question. The differences in estimates of forest area generated from remote sensing and forest inventories are not easy to reconcile because of definition problems.

The causes for the observed changes are not known but the spatial patterns in Fig. 9a offer some clues. Increased incidence of fires and infestations in Canada, fire suppression and forest regrowth in the USA, declining harvests in Russia, improved silviculture in the Nordic countries, woody encroachment and longer growing seasons from warming in the northern latitudes may explain some of the changes (Caspersen et al., 2000; Houghton et al., 1999; K eeling, Chin, \& Whorf, 1996; Kurz \& A pps, 1999; M yneni, K eeling, Tucker, A srar, \& Nemani, 1997). This implies uncertainty regarding the future of biomass sinks and therefore the need for monitoring. All of this suggests a cautionary reading of the results and need for further research. 
Nevertheless, this work contributes to global carbon cycle research in four ways. First, it provides spatial detail on the location of biomass carbon pools and where changes in this pool have occurred at a resolution that permits direct validation with ground data. Second, the NDVI data, when used in inversion studies, provide additional constraints to inferences regarding the distribution of sources and sinks for atmospheric $\mathrm{CO}_{2}$ and isotopic concentration data. Third, the inversion studies cannot partition the inferred sink between vegetation, soil and other pools. For example, if vegetation is a sink and soil is a source, estimates for changes in the vegetation pool would complement inversion results.

Finally, debate currently is underway regarding which of the forest biomass sinks can be used by the Annex 1 parties, the industrialized nations, to meet their commitment to reduce greenhouse gas emissions under the K yoto Protocol of the United Nations Framework Convention on Climate Change. Satellite estimates of biomass changes can be used to verify compliance (Nilsson et al., 2000), if the uncertainty of the remote sensing/statistical estimates can be further reduced. Improved observations of greenness levels from a new generation of spacecraft sensors such as the moderate-resolution imaging spectroradiometer and multiangle imaging spectroradiometer, and possibly direct biomass measurements with lidars, offer promise for the future.

\section{Acknowledgements}

This work was funded by NASA Earth Science Enterprise. We thank C. Day, I. Fung, J .E. Hansen, M .C. Hansen, M. Heimann, J. Knyazikhin, Y. Wang, N.V. Shabanov, D. Slayback and T.A. Stone for their contributions.

Appendix A . Lists of provinces, states and countries in Fig. 10

(a) The following provincial (Canada), state (USA) and national data were used in Fig. 10a.

Canada (11)

Alberta, M anitoba, N ew B runswick, Newfoundland, Northwest Territories, Nova Scotia, Ontario, Quebec, Saskatchewan, Yukon Territory.

Not included: B ritish Columbia

USA (46)

A labama, A laska, A rizona, A rkansas, Colorado, Connecticut, District of Columbia, Delaware, Florida, Georgia, Idaho, Illinois, Indiana, Iowa, K ansas, K entucky, L ouisiana, M aine, $M$ aryland, $M$ assachusetts, $M$ ichigan, $M$ innesota, $M$ ississippi, M issouri, M ontana, Nebraska, Nevada, New Hampshire, N ew Jersey, N ew M exico, New York, N orth Carolina, N orth Dakota, O hio, Oklahoma, Pennsylvania, R hode Island, South Carolina, South Dakota, Tennessee, Texas, Utah, Vermont, Virginia, West Virginia, Wisconsin, Wyoming.
Not included: California, Hawaii, Oregon, Washington Eurasian countries from TBFRA-2000 (37)

A lbania, A rmenia, A ustria, A zerbaijan, B elgium, B osnia, Bulgaria, B elarus, Croatia, Czech, Denmark, Estonia, FinIand, France, Georgia, Germany, Greece, Hungary, Ireland, Italy, J apan, K azakhstan, L atvia, Lithuania, N etherlands, N orway, Poland, Portugal, Romania, Slovakia, Slovenia, Spain, Sweden, Switzerland, Turkey, U kraine, United Kingdom.

Countries not included:

(1) Russia and China are given in Table 1

(2) Kyrgyzstan, Macedonia and U zbekistan: sink data not given in TBFRA-2000

(3) Cyprus, Iceland, Israel, Luxemburg, M oldova, Turkmenistan and Uzbekistan: forest area less than 0.1 million ha

USA (10)

A rkansas (1988, 1995), Florida (1987, 1995), Georgia (1989, 1997), M ississippi (1987, 1994), North Carolina (1984, 1990), South Carolina (1986, 1993), Texas (1986, 1992), Virginia (1986, 1992), W isconsin (1983, 1996).

(b) The following provincial (Sweden), state (USA) and national data were used in Fig. 10b.

USA (9)

A rkansas (1988, 1995), Florida (1987, 1995), Georgia (1989, 1997), M ississippi (1987, 1994), North Carolina (1984, 1990), Texas (1986, 1992), Virginia (1986, 1992), Wisconsin (1983, 1996).

South Carolina not included because it shows decrease in biomass.

Eurasian countries from TBFRA-2000 (37)

A lbania, A rmenia, A ustria, A zerbaijan, B elgium, B osnia, Bulgaria, Belarus, Croatia, Czech, Denmark, Estonia, Finland, France, Georgia, Germany, Greece, Hungary, Ireland, Italy, J apan, K azakhstan, L atvia, Lithuania, N etherlands, N orway, Poland, Portugal, Romania, Slovakia, Slovenia, Spain, Sweden, Switzerland, Turkey, U kraine, United Kingdom.

Countries not included:

(1) Russia and China are given in Table 1

(2) Kyrgyzstan, Macedonia and U zbekistan: sink data not given in TBFRA-2000

(3) Cyprus, Iceland, Israel, Luxemburg, M oldova, Turkmenistan, and Uzbekistan: forest area less than 0.1 million ha

Sweden (22)

Älvsborg, B lekinge, Gävleborg, Göteborg, G otland, Halland, J ämtland, Jönköping, K almar, K ronoberg, N orrbotten, Örebro, Östergötland, Skän, Skaraborg, Södermanland, Stockholm, Uppsala, Värmland, Västerbotten, Västernorrland, Västmanland.

N ot included: K opparberg because of data-quality issues

\section{References}

A lexeyev, V. A., \& Birdsey, R. A. (1998). Carbon storage in forests and peatlands of Russia. General Technical Report, NE-244, USDS Forest Service. 
Birdsey, R. A ., \& Heath, L. S. (1995). Productivity of A merica's forest and climatic change. In L.A. Joyce (Ed.), General Technical Report RM GTR 271 (pp. 56- 70). (USDA, Forest Service, Rocky M ountain Forest and Range Experiment Station, Fort Collins, CO, 1995).

B ousquet, P., Peylin, P., Ciais, P., Quéré, C. L., Friedlingstein, P., \& Tans, P. P. (2000). Regional changes in carbon dioxide fluxes of land and oceans since 1980. Science, 290, 1342- 1346.

Caspersen, J. P., Pacala, S. W., J enkins, J. C., H urtt, G. C., M oorcroft, P. R., $\&$ Birdsey, R. A . (2000). Contributions of land-use history to carbon accumulation in US forest. Science, 290, 1148- 1151.

Chen, J., Chen, W., Liu, J., Cihlar, J., \& Gray, S. (2000). A nnual carbon balance of Canada's forests during 1895 - 1996. G lobal Biogeochemical Cycles, 14, 839- 849 .

Christiano, L. J. (1992). Searching for a break in GN P. J ournal of Business \& Economic Statistics, 10(3), 237- 250.

Cost, N. D. (1990). The forest biomass resource of the United States. General Technical Report W0-57, United States Department of A griculture (USDA).

Dixon, R. K., Houghton, R. A., Solomon, A. M., Trexler, M. C., \& Wisniewski, J. (1994). Carbon pools and flux of global forest ecosystems. Science, 263, 185- 190.

Fang, J., Chen, A., Peng, C., Zhao, S., \& Ci, L. (2001). Changes in forest biomass carbon storage in China between 1949 and 1998. Science, 292, $2320-2322$.

FIA (2000). Forest Inventory and A nalysis data base at: www.srsfia.usfs. msstate.edu/scripts/ew.htm.

Hansen, M. C., D eFries, R. S., Townshend, J. R. G., \& Sohlberg, R. (2000). Global land cover classification at $1 \mathrm{~km}$ spatial resolution using a classification tree approach. International J ournal of Remote Sensing, 21, $1331-1364$.

Holben, B. N. (1986). Characteristics of maximum value compositing imagines for AVHRR data. International J ournal of Remote Sensing, 7, $1417-1437$

Houghton, R. A ., Hackler, J. L., \& Lawrence, K. T. (1999). The US carbon budget: contributions from land-use change. Science, 285, 574- 578.

Hsiao, C. (1986). Analysis of panel data. Cambridge: Cambridge Univ. Press.

IPCC (2000). Intergovermental Panel on Climate Change. Land U se, Land$\mathrm{U}$ se Change and Forestry. Cambridge: Cambridge Univ. Press (ISBN : 92-9169-114-3)

K aufmann, R. K., Zhou, L., Knyazikhin, Y., Shabanov, N. V., M yneni, R. J., \& Tucker, C. J. (2000). Effect of orbital drift and sensor changes on the rime series of AVHRR vegetation index data. IEEE Transactions on Geoscience and Remote Sensing, 38, $2584-2597$.

K eeling, C. D., Chin, J. F. S., \& Whorf, T. P. (1996). Increased activity of northern vegetation inferred from atmospheric $\mathrm{CO}_{2}$ measurements. Nature, 382, 146- 149 .

Kurz, W. A., \& Apps, M. J. (1999). A 70-year retrospective analysis of carbon fluxes in the Canadian forest sector. Ecological Applications, 9, $526-547$.

Liski, J., \& Kauppi, P. (2000). Woody biomass and the carbon cycle in Forest Resources of Europe, CIS, North A merica, A ustralia, Japan and $\mathrm{New}$ Zealand (industrialized temperate/boreal countries). UN-
ECE/FAO contributions to the global forest resources assessment (pp. 155-171). New York: United Nations.

LOS, S. O. (1998). Estimation of the ratio of sensor degradation between NOAA-AVHRR channels 1 and 2 from monthly NDVI composites. IEEE Transactions on Geoscience and Remote Sensing, 36, 206- 213.

Los, S. O., Justice, C. O., \& Tucker, C. J. (1994). A global $1^{\circ}$ by $1^{\circ}$ NDVI data set for climate studies derived from the GIM M S continental NDV I data. International J ournal of Remote Sensing, 15(17), 3493- 3518.

Lowe, J. J., Power, K., \& Gray, S. L. (1996). Canada's forest inventory 1991: the 1994 version. Information Report BC-X-362E, Pacific Forestry Centre, Victoria, B.C.

M yneni, R. B., K eeling, C. D., Tucker, C. J., A srar, G., \& Nemani, R. R. (1997). Increased plant growth in northern high latitudes from 19811991. Nature, 386, 698- 702.

M yneni, R. B., Tucker, C. J., A srar, G., \& Keeling, C. D. (1998). Interannual variations in satellite-sensed vegetation index data from 1981 to 1991. J ournal of Geophysical Research, 103(D6), 6145-6160.

Nilsson, S., Shvidenko, A., Stolbovoi, V., Gluck, M., Jonas, M., \& Obersteiner, M. (2000). Full carbon account for Russia. IIASA Interim Report IR-00-021, Laxenburg, A ustria.

Penner, M., Power, K., M uhairwe, C., Tellier, R., \& Wang, Y. (1997). Canada's forest biomass resources: deriving estimates from $C$ anada forest inventory. Information Report BC-X-370, Pacific Forestry Centre, Victoria, BC, Canada.

Rosborough, G. W., Baldwin, D. G., \& Emery, W. J. (1994). Precise AVHRR image navigation. IEEE Transactions on Geoscience and Remote Sensing, 32, 644-657.

Schulze, E. D., Wirth, C., \& Heimann, M . (2000). M anaging forests after K yoto. Science, 289, 2058- 2059.

Sedjo, R. A. (1992). Temperate forest ecosystems in the global carbon cycle. Ambio, 21, $274-277$.

Sedjo, R. A. \& Toman, M. (2001), Can Carbon Sinks Be Operational? Sedjo, R. A.\& Toman, M., Resources for the Future (RFF) Workshop Proceedings, 1616 P Street, NW, Washington, D.C., 1-5.

TBFRA-2000 (2000). Forest resources of Europe, CIS, North America, A ustralia, Japan and $\mathrm{New}$ Zealand (industrialized temperate/boreal countries). UN-ECE/FAO contributions to the global forest resources assessment (pp. 155-171). N ew York: U nited Nations.

Turner, D. P., K oerper, G. J., Harmon, M. E., \& L ee, J. J. (1995). A carbon budget for forests of the conterminous U nited States. Ecological Applications, 5, 421- 436 .

Vermote, E. E., \& EI Saleous, N. Z. (1994). Statospheric aerosol perturbing effect on remote sensing of vegetation: operational method for the correction of AVHRR composite NDVI. SPIE Atmospheric Sensing and Modeling, 2311, 19-29.

Vermote, E. F., \& K aufman, Y. J. (1995). A bsolute calibration of AVHRR visible and near-infrared channels using ocean and cloud views. International J ournal of Remote Sensing, 16, 2317- 2340.

Zhou, L., Tucker, C. J., K aufmann, K., Slayback, D., Shabanov, N. V., \& M yneni, R. B. (2001). Variation in northern vegetation activity inferred from satellite data of vegetation index during 1981 to 1999. J ournal of Geophysical Research, 106(D17), 20069- 20083. 